\title{
Strontium delivery systems based on bacterial cellulose and hydroxyapatite for guided bone regeneration
}

\author{
Erika Patricia Chagas Gomes Luz • Maria de Fátima Borges • Fabia Karine Andrade • \\ Morsyleide de Freitas Rosa • Antonia Infantes-Molina • Enrique Rodríguez-Castellón • \\ Rodrigo Silveira Vieira
}

Received: 6 February 2018/Accepted: 20 August 2018/Published online: 29 August 2018

(C) Springer Nature B.V. 2018

\begin{abstract}
Hybrid materials (HMs) based on a combination of bacterial cellulose (BC) and hydroxyapatite (HA) have demonstrated promising capabilities, especially for bone repair. The insertion of strontium into a $\mathrm{BC} / \mathrm{HA}$ matrix has a role in the body related to bone remodeling. This study aimed to obtain HMs containing BC/HA doped with strontium ions $\left(\mathrm{Sr}^{2+}\right)$ by two routes of synthesis, differing in the way strontium was inserted. The HMs produced were characterized to elucidate the morphology and metal/ biopolymer interaction, and also strontium adsorption/ desorption profiles were evaluated. The biomaterials produced were able to interact with $\mathrm{Sr}^{2+}$, showing a distinct adsorption/desorption profile for each
\end{abstract}

material. $\mathrm{BC} / \mathrm{CaHA} / \mathrm{Sr}$ showed an ion exchange between $\mathrm{Ca}^{2+}$ present in hydroxyapatite by the $\mathrm{Sr}^{2+}$ in solution, characterized by mainly a physisorption mechanism. BC/SrAp demonstrated a chemical bond of $\mathrm{Sr}^{2+}$ on the $\mathrm{BC}$ surface by a chemisorption mechanism. The desorption study showed that the $\mathrm{Sr}$ release reached a plateau after 11 and 60 days and after 4 months, 91 and $6 \%$ of the adsorbed $\mathrm{Sr}^{2+}$ was released by $\mathrm{BC} / \mathrm{CaHA} / \mathrm{Sr}$ and $\mathrm{BC} / \mathrm{SrAp}$, respectively. These results suggest that the delivery of $\mathrm{Sr}^{2+}$ can be modulated during bone repair depending on the way $\mathrm{Sr}^{2+}$ is inserted into the hybrid matrix.

E. P. C. G. Luz · F. K. Andrade · R. S. Vieira ( $\square)$

Department of Chemical Engineering, Federal University of Ceará (UFC), Bloco 709, Fortaleza, Ceará 60455-760, Brazil

e-mail: rodrigogpsa@gmail.com

M. F. Borges · F. K. Andrade - M. F. Rosa Embrapa Agroindústria Tropical-CNPAT, Rua Dra Sara Mesquita 2270, Pici, Fortaleza, Ceará 60511-110, Brazil

A. Infantes-Molina · E. Rodríguez-Castellón Departamento de Química Inorgánica, Facultad de Ciencias (Unidad Asociada al ICP-CSIC), Universidad de Málaga, 29071 Málaga, Spain 


\section{Graphical abstract}

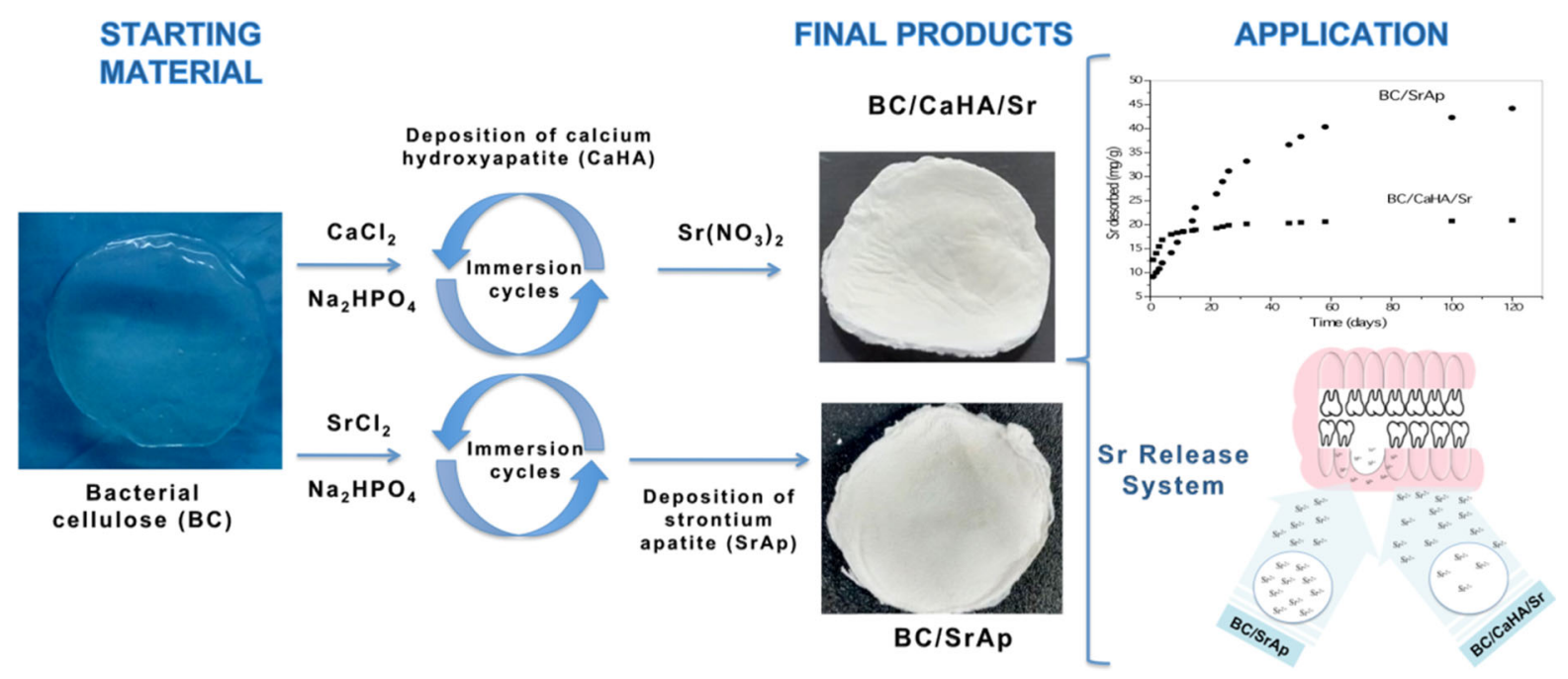

Keywords Biomaterials - Bone repair - Release systems $\cdot$ Bone tissue

\section{Introduction}

Guided bone regeneration is a method successfully employed in dental practices to increase the volume of the host bone at sites with insufficient bone quantity. Thus, before the dental implants can be surgically anchored into the jawbone via titanium screws, the reconstruction of deficient alveolar ridges is necessary to facilitate implant placement. For that, oral surgeons fill the socket with bone graft (allograft bone chips or ceramic particles) to stimulate new bone growth. To ensure the graft stays in place, the site is typically covered with a membrane, however the particles from the traditional bone grafts frequently leak and migrate, which could damage the surrounding soft tissues (e.g. gingiva, nerves, and sinus membranes; Hutchens 2007). Besides avoiding the migration of the allograft bone chips or ceramic particles, this membrane barrier is used in guided bone regeneration (GBR) to protect the defect area against the invasion of non-osteogenic tissues that have a higher migration velocity than osteogenic cells. Membrane barriers must have characteristics that lead to biological, mechanical and clinical use requirements to serve as a barrier against unwanted cell invasion since these cells inhibit bone formation and stimulate the down-growth of the connective tissue into the area of injured tissue ( $\operatorname{Rad}$ et al. 2017). Some of the indispensable requirements to act as a passive physical barrier are: biocompatibility, cell occlusion properties, capacity to create a secluded space, tissue integration and be clinically handled. Moreover, clinical reports found in the literature show that both absorbable and nonabsorbable membranes are effective in the process of guided bone regeneration, provided that an adequate technical protocol is applied in each case, in order to minimize complications (Rakhmatia et al. 2013; Retzepi and Donos 2010).

Hybrid materials (HM) obtained from bacterial cellulose (BC) and hydroxyapatite (HA) have been shown to be promising materials for use in guided bone regeneration (GBR) (Grande et al. 2009; Saska et al. 2011), since BC is a biopolymer with excellent biocompatibility, high mechanical properties, high crystallinity, and high water retention capacity (Ahn et al. 2015; Duarte et al. 2015; Pértile et al. 2012; Rajwade et al. 2015) while HA is a ceramic that naturally constitutes bones and teeth and has high biocompatibility, stability at physiological $\mathrm{pH}$, and stimulates osteointegration (Pigossi et al. 2015). One advantage of using $\mathrm{BC} / \mathrm{CaHA}$ hybrids is that, since the HA particles are physically bound to cellulose fibers, this type of system prevents the HA particles from migrating to neighboring areas, which avoids damage of the surrounding soft tissues, making the application 
of an extra membrane to cover the graft unnecessary (Hutchens 2007).

Recently, our group synthesized a biocompatible biomaterial based on $\mathrm{BC}$ and hydroxyapatite. In this case, a calcium-deficient apatite, which is similar to biological apatites, was deposited on the cellulose fibers. The biocomposite presented in vitro bioactivity and was suitable for the preparation of nanocomposites for applications in the regeneration of bone tissue (Duarte et al. 2015).

In this sense, in the present work, aiming to enhance the benefits of $\mathrm{BC} / \mathrm{HA}$ composites in promoting bone remodeling mechanisms, strontium ions $\left(\mathrm{Sr}^{2+}\right)$ were incorporated into this hybrid material. Literature relates that preclinical studies demonstrated strontium action mechanisms on bone modeling and confirmed its role as an inhibitor of bone reabsorption, reducing the activity of osteoclasts (Schumacher et al. 2016) while at the same time inducing bone formation by stimulating osteoblast activity (Marie et al. 2010; Zhang et al. 2011). Its dual action is related to its chemical similarity to calcium (Querido et al. 2016). Calcium is a necessary nutrient for the functioning of the human body, since it is involved in many reactions, such as bone formation, muscle contraction, enzyme activation, cell differentiation, programmed cell death, and neuronal activity (Chen et al. 2012; Wang et al. 2009; Zhang et al. 2014; Zhong et al. 2013; Zhou et al. 2012).

In the present study, bacterial cellulose/hydroxyapatite hybrids functionalized with strontium ions were characterized in relation to their chemical structure, morphology, porosity, surface composition, their power of swelling degree and their capacity of adsorption and desorption. The adsorption/desorption of $\mathrm{Sr}^{2+}$ by the HM was also evaluated in order to know the delivery rate of this metal ion and to elucidate the metal/biopolymer interaction.

\section{Materials and methods}

Reagents and media components

Bacteriological agar, casein peptone, and yeast extract powder were purchased from Difco ${ }^{\mathrm{TM}}$ (Detroit, Michigan, USA). Citric acid hydrate, $d(+)$ glucose anhydrous, sodium dihydrogen phosphate anhydrous, and sodium hydroxide and were purchased from Sigma-Aldrich (St. Louis, Missouri, USA).

Microorganism and media preparation

Komagataeibacter hansenii ATCC 23769 strain was used as the BC-producing bacterial source. The strain was previously stored at $-18{ }^{\circ} \mathrm{C}$ in mannitol broth $(5.0 \mathrm{~g} / \mathrm{L}$ of yeast extract; $3.0 \mathrm{~g} / \mathrm{L}$ of peptone, and $2.5 \mathrm{~g} / \mathrm{L}$ of d-mannitol) containing $20 \%$ glycerol (w/v). The activation was performed in mannitol broth and the bacteria was cultured statically at $30{ }^{\circ} \mathrm{C}$ for 2 days. The culture was propagated by inoculation of $3 \%(\mathrm{v} / \mathrm{v})$ from mannitol broth to HS medium (Hestrin and Schramm 1954) at $30{ }^{\circ} \mathrm{C}$ for $48 \mathrm{~h}$. Finally, the inoculum was added to Falcon tubes containing $20 \mathrm{~mL}$ HS media and incubated at $30{ }^{\circ} \mathrm{C}$ for 6 days. The $\mathrm{BC}$ pellicles were purified with $2 \%$ sodium hydroxide and sterilized by exposure to $121{ }^{\circ} \mathrm{C}$ for $30 \mathrm{~min}$.

\section{Hybrid production}

In this present study, bacterial cellulose/hydroxyapatite hybrids functionalized with strontium ions were synthesized by two different routes. For the synthesis of the first hybrid, the hybrid (BC/CaHA) was produced followed by its immersion in strontium nitrate solution to promote the exchange of calcium ions by strontium ions. For the synthesis of the second hybrid, the strontium ions were directly introduced into the $\mathrm{BC}$ matrix leading to the precipitation of strontium apatite on the $\mathrm{BC}$ fibers.

The first route was conducted as proposed by Hutchens et al. (2006) and is described as follows: After purification, the $\mathrm{BC}$ pellicles $(25 \mathrm{~mm})$ were immersed in $25 \mathrm{~mL} \mathrm{CaCl}$ solution $(11.1 \mathrm{~g} / \mathrm{L})$ and mildly stirred at $25{ }^{\circ} \mathrm{C}$ for $24 \mathrm{~h}$. Thereafter, for the removal of $\mathrm{CaCl}_{2}$ excess, the pellicles were washed with deionized water, followed by immersion in $25 \mathrm{~mL}$ of $\mathrm{Na}_{2} \mathrm{HPO}_{4}$ solution $(8.52 \mathrm{~g} / \mathrm{L})$ using the same conditions previously described. This alternate soaking process (immersion in calcium and phosphate solutions) was repeated three times with the samples rinsed thoroughly with deionized water between each soaking cycle $(\sim 10 \mathrm{~mL}$ of deionized water for $3 \mathrm{~min}$ at $25^{\circ} \mathrm{C}$ ). Finally, the composite $\mathrm{BC} / \mathrm{CaHA}$ was removed and freeze-dried. For incorporation of strontium, the $\mathrm{BC} / \mathrm{CaHA}$ composite was immersed in 
strontium nitrate solution $(100 \mathrm{mg} / \mathrm{L})$ at $40{ }^{\circ} \mathrm{C}$ for $2 \mathrm{~h}$ leading to the production of the $\mathrm{BC} / \mathrm{CaHA} / \mathrm{Sr}$ hybrid.

For the second method, strontium hydroxyapatite was directly deposited onto the $\mathrm{BC}$ fibers to produce the $\mathrm{BC} / \mathrm{SrAp}$ hybrid according to the methodology described by Hutchens et al. (2006) with adaptation. For this, alternate soaking of BC pellicles in $25 \mathrm{~mL}$ of $\mathrm{SrCl}_{2}$ solution $(100$ or $1000 \mathrm{mg} / \mathrm{L})$ and $\mathrm{Na}_{2} \mathrm{HPO}_{4}$ solution $(8.52 \mathrm{~g} / \mathrm{L})$ under gentle agitation at $25{ }^{\circ} \mathrm{C}$ for $24 \mathrm{~h}$ was performed. This process was repeated five times with the samples rinsed thoroughly with deionized water between each soaking cycle $(\sim 10 \mathrm{~mL}$ of deionized water for $3 \mathrm{~min}$ at $25^{\circ} \mathrm{C}$ ), and the BC/SrAp was freeze-dried. To evaluate the $\mathrm{Sr}^{2+}$ incorporation into the hybrid matrix after each cycle, aliquots from the aqueous phase were taken and analyzed by atomic absorption spectrometry (AAS).

Swelling degree and porosity

The swelling degree was assessed using the method described by Liu et al. (2005). The hybrids produced were immersed in phosphate buffered saline (PBS) at pH 7.4 during intervals of $0,1,2,7,12,22,32,52$, and $72 \mathrm{~min}$ at $25{ }^{\circ} \mathrm{C}$. After each immersion, the excess buffer was removed with filter paper and the pellicle was weighed. The porosity of the hybrids was obtained as described by Zeng and Ruckenstein (1996). Porosity was determined by considering the amount of water inside the pores, taking in account the weight of the wet and dry (lyophilized) sample.

The swelling degree (SD) was expressed as the percentage of weight increase compared to the initial weight, as described in Eq. 1:

$\mathrm{SD}=\left(\mathrm{W}_{\mathrm{s}}-\mathrm{W}_{\mathrm{d}} / \mathrm{W}_{\mathrm{d}}\right) \times 100$

The porosity $(\varepsilon)$ is estimated by Eqs. 2 and 3 .

$$
\begin{aligned}
& \varepsilon(\%)=\left\{\left(\mathrm{W}_{\mathrm{s}}-\mathrm{W}_{\mathrm{d}}\right) / \rho_{\text {water }}\right\} \times 100 / \mathrm{v} \\
& \mathrm{v}=\left(\pi \mathrm{D}^{2} \mathrm{~h}\right) / 4
\end{aligned}
$$

where $\mathrm{W}_{\mathrm{s}}$ is the weight of the sample after immersion, and $\mathrm{W}_{\mathrm{d}}$ is the weight of the dry sample before immersion, $\varepsilon$ is the porosity of the membrane and $\rho_{\text {water }}$ is the specific mass of water at $20{ }^{\circ} \mathrm{C}$, v is volume of the pellicle, $\mathrm{D}$ is the diameter and $\mathrm{h}$ is the height.
Scanning electron microscopy (SEM) and energydispersive X-ray spectroscopy (EDX)

Before SEM and EDX analyses the lyophilized samples were placed in a stub and sputter-coated with gold. The SEM images were obtained with a DSM 940A scanning electron microscope (SEM; Zeiss, Germany) with an acceleration voltage of $15 \mathrm{kV}$. EDX analyses were obtained using an Inspect S50 scanning electron microscope (FEI, Hillsboro, Oregon, USA) with an acceleration voltage of $10 \mathrm{kV}$.

$\mathrm{N}_{2}$-adsorption isotherms

The surface area and the pore diameter of the samples were experimentally determined by nitrogen adsorption/desorption isotherms at $-196{ }^{\circ} \mathrm{C}$ using a Micromeritics ASAP 2020 analyzer. The samples were previously degassed at $200{ }^{\circ} \mathrm{C}$ in a vacuum of $10^{-5}$ bar. The textural properties were calculated according the BET technique (Brunauer et al. 1938).

Fourier-transform infrared spectroscopy (FTIR)

The FTIR spectrum analysis was conducted to confirm the functional groups in the hybrid materials. Samples were examined using an FTLA 2000-102 (ABBBOMEM) spectrophotometer equipped with an attenuated total reflectance (ATR) accessory. Spectra were obtained between 4000 and $400 \mathrm{~cm}^{-1}$ at a resolution of $4 \mathrm{~cm}^{-1}$ over 25 scans.

Solid state nuclear magnetic resonance (NMR)

${ }^{31} \mathrm{P}$ and ${ }^{13} \mathrm{C}$ MAS NMR spectra were recorded at room temperature with a Bruker AVANCEIII HD 600 spectrometer using an HXY, Efree MAS probe of $3.2 \mathrm{~mm}$ at a spinning rate of $15 \mathrm{kHz}$. The magnetic field was $14.1 \mathrm{~T}$ corresponding to ${ }^{13} \mathrm{C}$ and ${ }^{31} \mathrm{P}$ resonance frequencies of 150.9 and $242.9 \mathrm{MHz}$, respectively. All spectra were recorded using a CPMAS pulse program: a combination of cross-polarization, high-power proton decoupling, and magic angle spinning. The ${ }^{13} \mathrm{C}$ chemical shift values were measured with respect to glycine as a secondary reference (carbonyl signal at $176.03 \mathrm{ppm}$ ) and ${ }^{31} \mathrm{P}$ with respect to ammonium dihydrogen phosphate at $0.9 \mathrm{ppm}$. 
X-ray photoelectron spectroscopy (XPS)

X-ray photoelectron spectra were collected using a Physical Electronics PHI 5700 spectrometer with nonmonochromatic $\mathrm{MgK} \alpha$ radiation $(300 \mathrm{~W}, 15 \mathrm{kV}$, and $1253.6 \mathrm{eV}$ ) with a multi-channel detector. Spectra were recorded in the constant pass energy mode at $29.35 \mathrm{eV}$, using a $720 \mu \mathrm{m}$ diameter analysis area. Charge referencing was measured against adventitious carbon (C $1 \mathrm{~s}$ at $284.8 \mathrm{eV}$ ). A PHI ACCESS ESCAV6.0 F software package was used for acquisition and data analysis. A Shirley-type background was subtracted from the signals. Recorded spectra were always fitted using Gaussian-Lorentzian curves in order to determine the binding energy of the different element core levels more accurately.

Adsorption studies with the hybrid BC/CaHA/Sr

\section{Adsorption kinetics of Sr ions}

Batch experimental studies were carried out with a fixed mass ( $0.035 \mathrm{~g}$ of dry weight) of adsorbent in strontium nitrate solution of $100 \mathrm{mg} / \mathrm{L}$, under controlled temperature conditions at $25{ }^{\circ} \mathrm{C}$ and $\mathrm{pH}$ 6.0. $\mathrm{BC} / \mathrm{CaHA}$ pellicles were immersed in $\mathrm{Sr}$ solutions and agitated using rotary shaker tubes (TE-165 TECNAL) at $45 \mathrm{rpm}$. At intervals of $0.25,0.5,1,2$, and $3 \mathrm{~h}$, the adsorbent was removed and the aqueous-phase concentration of the metal was determined with an atomic absorption spectrophotometer (AA240FS FAST sequential atomic absorption spectrometer).

\section{Effect of $p H$}

The effect of $\mathrm{pH}$ on adsorption of $\mathrm{Sr}^{2+}$ was evaluated. The experiments were conducted in batch mode using a fixed mass of the adsorbent ( $0.035 \mathrm{~g}$ of dry weight) immersed in strontium nitrate solutions $(100 \mathrm{mg} / \mathrm{L})$ at $\mathrm{pH}$ values ranging from 2.0 to 6.0 at room temperature for $2 \mathrm{~h}$. The $\mathrm{pH}$ of the solution was adjusted using $0.1 \mathrm{M} \mathrm{NaOH}$ and $0.1 \mathrm{M} \mathrm{HCl}$.

\section{Temperature effect on Sr adsorption}

To study the influence of temperature on the adsorption of $\mathrm{Sr}$ ions by the BC/CaHA hybrid, strontium nitrate solutions were prepared at a concentration of $100 \mathrm{mg} / \mathrm{L}$ at $\mathrm{pH} 6.0$, using a fixed mass of the adsorbent ( $0.035 \mathrm{~g}$ of dry weight) for a period of $2 \mathrm{~h}$. The experiments were performed at temperatures of 20, 25, 30, and $40{ }^{\circ} \mathrm{C}$.

\section{Adsorption isotherm}

Adsorption isotherms were performed in a batch system using $0.035 \mathrm{~g}$ of adsorbent in $25 \mathrm{~mL}$ of strontium nitrate solution at a concentration range of 10-350 mg/L, at pH 6.0. A thermostatic bath at $25^{\circ} \mathrm{C}$ or $40{ }^{\circ} \mathrm{C}$ under constant stirring $(150 \mathrm{rpm})$ was used. After $2 \mathrm{~h}$, the adsorbent was removed and the aqueous-phase concentration of metal was determined by atomic absorption spectrometry (AAS) at a wavelength of $460 \mathrm{~nm}$. In order to increase the analysis sensitivity as air-acetylene gas was used, $2 \mathrm{~mL}$ of chloride potassium solution $(10.000 \mathrm{mg} / \mathrm{L})$ and $0.2 \mathrm{~mL}$ of $50 \%$ lanthanum were added to eliminate any interference, to each $10 \mathrm{~mL}$ sample.

Sr desorption studies

The desorption profiles of $\mathrm{Sr}$ ions from the two hybrid materials were evaluated in order to determine the $\mathrm{Sr}^{2+}$ delivery rate and elucidate metal/adsorbent interactions. Experiments to measure the amount of strontium desorbed were performed by immersing $0.035 \mathrm{~g}$ of dry weight of the hybrid sample in $10 \mathrm{~mL}$ of phosphate buffered saline (PBS) at $\mathrm{pH} 7.4,37{ }^{\circ} \mathrm{C}$ under stirring $(150 \mathrm{rpm})$. At each time studied, an aliquot of $3 \mathrm{~mL}$ was collected, the remaining volume of the buffer was discarded, and finally $10 \mathrm{~mL}$ of fresh PBS was added. Aliquots from each time point were analyzed by AAS to quantify the amount of strontium desorbed.

\section{Results and discussion}

Swelling degree

The main mechanisms that influence the swelling are the diffusion of the penetrating solvent and polymer stability (Capitani et al. 2001). This process is of considerable importance and allows for determination of the interaction of the material with solvents.

The swelling of the hybrid materials occurred rapidly, indicating that its structure facilitated water penetration, allowing interaction with the polymer 
matrix. The BC/SrAp hybrid obtained the highest swelling degree of $1019 \pm 0.03 \%$, followed by $\mathrm{BC} /$ $\mathrm{CaHA} / \mathrm{Sr} \quad(961 \pm 0.13 \%)$ and BC/CaHA $(894 \pm 0.05 \%)$ (Fig. 1).

These results suggest that there are hydrophilic groups available in the polymer structure, with different levels of hydrophilicity, and they are related to the water affinity of the groups of the polymer and apatite. The $\mathrm{Sr}$ insertion in the composite matrix lead to solubility of some of the deposited apatite, which was in agreement with the study of Pan et al. (2009) which showed the solubility isotherms of partially and fully substituted strontium hydroxyapatite. The increase in solubility with higher strontium content was interpreted as a destabilization of the crystal structure by the larger strontium ion.

From the swelling test it was possible to estimate the porosity of the materials using both the dry and wet weights. Membranes used in GBR should allow the diffusion of interstitial fluid, at the same time that inhibits the invasion of cells from connective and epithelial tissue (Retzepi and Donos 2010). Transport of oxygen and nutrients and metabolic waste removal through the membrane is mainly a function of diffusion, which is governed by its porosity and permeability. Moreover, high porosity provides more sites for the binding of a delivered compound (e.g., strontium metal ions).

The BC/CaHA presented a large volume of pores corresponding to $83 \%$, which favors strontium adsorption, facilitating the interaction between adsorbate and adsorbent. However, after the immersion of BC/CaHA in strontium nitrate solution for the production of the functionalized $\mathrm{BC} / \mathrm{CaHA} / \mathrm{Sr}$ hybrid, the porosity decreased to $72 \%$. The $\mathrm{BC} / \mathrm{SrAp}$ hybrid presented a porosity of $84 \%$, similar to $\mathrm{BC} / \mathrm{CaHA}$. For nonresorbable membrane (e.g., BC implants), there is a general consensus that implant porosity should be above $60 \%$, as below this value sustainable bone integration into the central pore chambers cannot be expected (Hing 2005).

\section{Scanning electron microscopy (SEM)}

The morphology of raw bacterial cellulose fibers is shown in Fig. 2a. The BC network includes nanofibrils (the width of the fibers is in the nanometer range) and is considered highly porous (Fig. 2a). This type of 3D structure makes BC an outstanding material for drug transfer and as a physical barrier, and in the last several decades it has been used as a wound dressing and for bone regeneration (Zimmermann et al. 2011).

In Fig. 2b, it is possible to observe the morphology of the BC/CaHA matrix. After the deposition of hydroxyapatite through immersion cycles in calcium and phosphate solutions, the BC surface was completely covered by globular crystallites typical of calcium apatite, as described by other authors (Duarte et al. 2015).

The structure found in Fig. 2c showed that after the $\mathrm{BC} / \mathrm{CaHA}$ was immersed in strontium nitrate solution in order to incorporate this metal in the matrix of the hybrid material some hydroxyapatite crystals present on the surface of the composite seemed to dissolve in the aqueous phase. BC fibers between crystallites became exposed and could be visualized, which corroborates the porosity and swelling degree results.

Figure $2 \mathrm{~d}$ shows that the apatite formed on $\mathrm{BC}$ fibers from strontium phosphate solution is morphologically similar to the hydroxyapatite formed from calcium phosphate solution (Fig. 2b). Melnikov and Gonçalves (2015) synthesized and characterized strontium hydroxyapatite $\left(\mathrm{Sr}_{10}\left(\mathrm{PO}_{4}\right)_{6}(\mathrm{OH})_{2} \cdot 10 \mathrm{H}_{2} \mathrm{O}\right)$ for orthopedic applications. The morphological analyses by SEM of SrAp samples showed that the crystals formed at room temperature were tiny irregular granules of around $5 \mathrm{~nm}$ in diameter. However, with the increase in temperature, the granules increased in size and exhibited star-like aggregates composed of a mean needle length of $5100 \mathrm{~nm}$ and a diameter of $340 \mathrm{~nm}$.

$\mathrm{N}_{2}$-Adsorption/desorption isotherms

The textural properties, such as surface area and pore diameter, are relevant to determine the accessibility of the adsorption sites. The specific surface area, average pore diameter, and specific volume of the pores of the materials were determined by the BET method, and the results obtained are shown in Table 1.

The nitrogen adsorption isotherms at $-196{ }^{\circ} \mathrm{C}$ for $\mathrm{BC}, \mathrm{BC} / \mathrm{CaHA}, \mathrm{BC} / \mathrm{CaHA} / \mathrm{Sr}$, and $\mathrm{BC} / \mathrm{SrAp}$ samples present a type IV profile with $\mathrm{H} 3$ hysteresis, which is a characteristic of mesoporous materials (pore sizes of 2-50 nm), according to IUPAC classification. These isotherms present an adsorption curve that does not overlap the nitrogen desorption curve, which is associated with the phenomenon of capillary 
condensation, where saturation pressures are not equal inside the pores, causing hysteresis (Ceratti et al. 2015).

The results presented in Table 1 indicate that the measurements of the surface area properties, specific pore volume, and average pore diameter increased after the interaction of $\mathrm{BC}$ with calcium HA. The literature reports that $\mathrm{HA}$ is an inorganic solid that has a surface area around $48 \mathrm{~m}^{2} / \mathrm{g}$ (Venugopal and Scurrell 2003) which is larger than the BC surface area, indicating the benefit of $\mathrm{BC}$ and $\mathrm{HA}$ interaction. Moreover, the HMs presented pore sizes less than $25 \mathrm{~nm}$. It is know that a pore size $<1 \mu \mathrm{m}$ results in a larger surface area that is believed to contribute to the bioactivity and bone-inducing protein adsorption (Vallet-Regí and Ruiz-Hernández 2011). In general, these hybrid membranes are an highly porous material, which facilitates the adsorption of strontium (as it will be showed in next sections) and probably also the passage of interstitial fluids and oxygen. In addition, due to the small pore sizes, will also act as a barrier preventing the invasion of non-osteogenic cells in the region that it is intended to promote bone repair.

Comparing the average pore diameter of $\mathrm{BC} / \mathrm{CaHA}$ with $\mathrm{BC} / \mathrm{CaHA} / \mathrm{Sr}$ and $\mathrm{BC} / \mathrm{SrAp}$ hybrids, the decrease was probably because of the insertion of the strontium metal in its structure. This result is related with the swelling and porosity results, which is evidenced by some solubilization of the HA matrix.

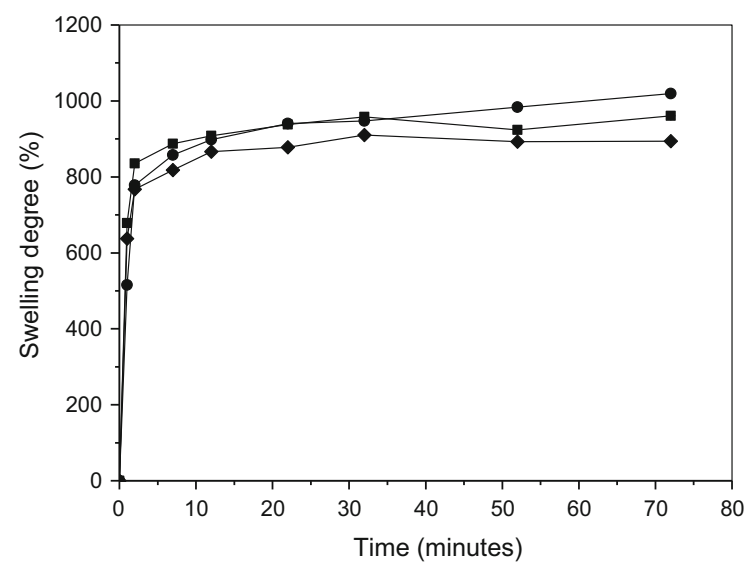

Fig. 1 Swelling degree of hybrid materials produced in PBS buffer at $\mathrm{pH}$ 7.4. BC/CaHA/Sr (

, BC/SrAp (O) and BC/CaHA
Fourier-transform infrared spectroscopy (FTIR)

The infrared analyses were performed in order to characterize the functional groups presented in each hybrid material.

The FTIR spectra of the hybrid materials are displayed in Fig. 3, and the band assignments are summarized in Table 2 In the vibrational spectra of native $\mathrm{BC}$, typical vibration bands of the cellulose structure appeared at $3350 \mathrm{~cm}^{-1}(\mathrm{O}-\mathrm{H}$ bond stretching), 2900-2850 $\mathrm{cm}^{-1}$ (stretching of $\mathrm{CH}$ and asymmetric stretching of $\mathrm{CH}_{2}$ ), $1426 \mathrm{~cm}^{-1}$ (asymmetric angular deformation of C-H bonds), $1360-1378 \mathrm{~cm}^{-1}$ (symmetric angular deformation of $\mathrm{C}-\mathrm{H}$ bonds), $1060 \mathrm{~cm}^{-1}$ (asymmetrical stretching of $\mathrm{C}-\mathrm{O}-\mathrm{C}$ glycosidic bonds), and $107-1055 \mathrm{~cm}^{-1}$ (stretching of C$\mathrm{OH}$ and $\mathrm{C}-\mathrm{C}-\mathrm{OH}$ bonds for secondary and primary alcohols, respectively). We also observed bands corresponding to $\mathrm{C}-\mathrm{H}$ bond bending or $\mathrm{CH}_{2}$ stretching at $900 \mathrm{~cm}^{-1}$, as well as $\mathrm{O}-\mathrm{H}$ out-of-plane bending at $665 \mathrm{~cm}^{-1}$ (Dufresne 2012; Gea et al. 2011; Ummartyotin et al. 2017).

The vibrational spectra of all three hybrids (Fig. 3), did not show the absorption bands at 2919-2850 $\mathrm{cm}^{-1}$, commonly found in BC, probably because of the intense absorption by the structural skeleton of apatite. Bands related to phosphate groups were present only in the vibrational spectra of $\mathrm{BC} /$ $\mathrm{CaHA}$ and BC/SrAp at the same time that the band around $1400 \mathrm{~cm}^{-1}$ was only found in $\mathrm{BC} / \mathrm{CaHA} / \mathrm{Sr}$ and native $\mathrm{BC}$. These observations corroborate the observation obtained by SEM results, which showed that after the $\mathrm{BC} / \mathrm{CaHA}$ was immersed in strontium nitrate solution, some of the hydroxyapatite crystals present on the surface of the composite were dissolved to the aqueous phase, thus exposing the network of cellulose fibers.

These results are confirmed by NMR, since it indicates that the samples show characteristics of cellulose due to the presence of the basic unit, glucose. It also indicates that the formation of hybrids results from the interaction of $\mathrm{Ca}, \mathrm{Sr}$, and $\mathrm{P}$ with hydroxyl groups, showing a preferential substitution in this position.

Solid state NMR spectroscopy

${ }^{13} \mathrm{C}$ CP-MAS profiles (Fig. 4) show the characteristic peaks of cellulose. In general, it is clearly observed a 
Fig. 2 Electron micrographs of the surfaces from raw bacterial cellulose (a), and the hybrid materials $\mathrm{BC} / \mathrm{CaHA}$ (b), BC/CaHA/Sr (c), and BC/SrAp (d)
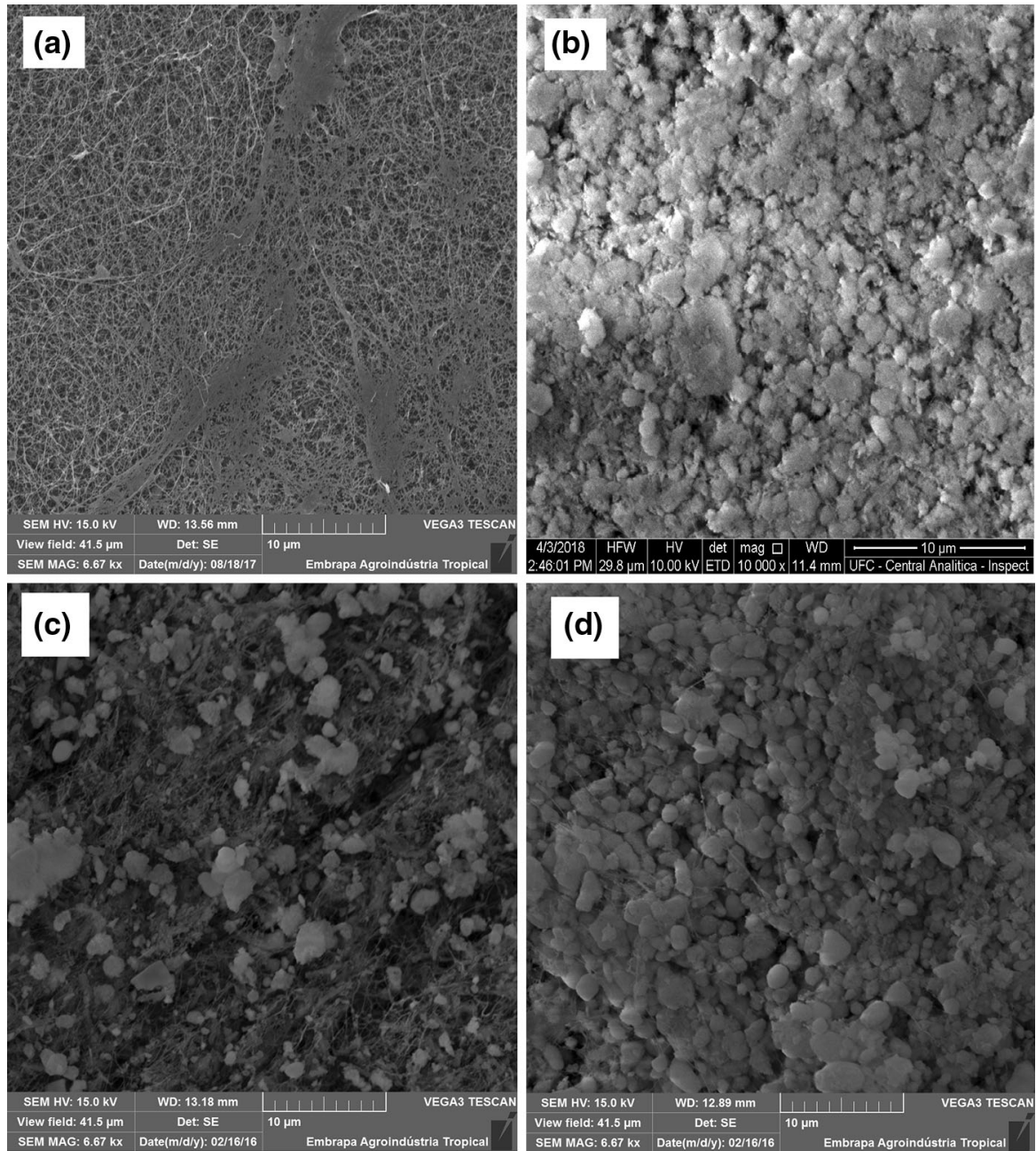

decrease in the relative intensity of all resonance signals after the inorganic inclusion. If the spectra are compared, the peaks in the range of $60-105 \mathrm{ppm}$ associated with anhydrous glucose units (Heinze et al. 2014; Foresti et al. 2017) are those affected by $\mathrm{Ca}, \mathrm{Sr}$ and $\mathrm{P}$ insertion. The signal corresponding to C6 carbon bearing $\mathrm{OH}$ groups changes shifting at higher values, indicating a preferential substitution in that position (Fig. 4).

${ }^{31} \mathrm{P}$ CP-MAS analysis confirmed that phosphate groups are chemically bonded to the material. The sample without $\mathrm{Sr}, \mathrm{BC} / \mathrm{CaHA}$, shows three main contributions located at $1.4,-0.3$ and $-2.0 \mathrm{ppm}$. These values are close to those reported in literature for $\mathrm{PO}_{4}{ }^{3-}, \mathrm{HPO}_{4}{ }^{2-}$ and $\mathrm{H}_{2} \mathrm{PO}_{4}{ }^{-}$ions, respectively (Lin et al. 2005). After $\mathrm{Sr}$ incorporation into this material, the main signal observed was that at
$1.4 \mathrm{ppm}$, indicating that $\mathrm{PO}_{4}{ }^{3-}$ ions are those present in this sample. Moreover, a small contribution at $4.5 \mathrm{ppm}$ could be due to isolated $\mathrm{PO}_{4}{ }^{3-}$ units (Lin et al. 2005). The spectrum for $\mathrm{BC} / \mathrm{SrAp}$ is again different. ${ }^{31} \mathrm{P}$ chemical shift for $\mathrm{Sr}$ hydroxyapatite is reported at $2.2 \mathrm{ppm}$ (Sugiyama 2003) and could correspond to the band at $1.7 \mathrm{ppm}$. However, the most important contributions are located between -2.4 and $-3.4 \mathrm{ppm}$. That could correspond to Sr-type phosphate without apatite structure. Previous studies reveal that $\mathrm{Sr}$ retards apatite-like phase formation (Henderson et al. 2016). By comparing all the spectra, it is clearly observed that after $\mathrm{Sr}$ incorporation into $\mathrm{BC} / \mathrm{CaHA}$, it is observed only one type of phosphate, pointing to a cationic $\mathrm{H}-\mathrm{Sr}$ exchange and indicating that $\mathrm{Sr}$ is incorporated in the $\mathrm{HPO}_{4}{ }^{2-}$ and $\mathrm{H}_{2} \mathrm{PO}_{4}{ }^{-}$ groups of $\mathrm{BC} / \mathrm{CaHA}$ sample. These results indicate 
Table 1 Textural properties of BC, BC/CaHA, BC/CaHA/Sr, and BC/SrAp obtained through the nitrogen adsorption/desorption isotherms

\begin{tabular}{llll}
\hline Sample & Specific surface area $\left(\mathrm{m}^{2} / \mathrm{g}\right)$ & Specific volume of pores $\left(\mathrm{cm}^{3} / \mathrm{g}\right)$ & Average pore diameter $(\mathrm{nm})$ \\
\hline BC & 22 & 0.102 & 18.3 \\
BC/CaHA & 59 & 0.354 & 24 \\
BC/CaHA $/ \mathrm{Sr}$ & 36 & 0.118 & 12.8 \\
BC/SrAp & 86 & 0.287 & 13.2 \\
\hline
\end{tabular}

different chemical coordination of Sr with and without calcium. In the former case, $\mathrm{Sr}$ is forming a hydroxyapatite structure, but in the latter case, Sr-type phosphate, without apatite structure is also present and could play an important role in the Sr-release process.

The surface composition of these materials was evaluated by means of X-ray photoelectron spectroscopy. C $1 s, \mathrm{O} 1 s, \mathrm{P} 2 p, \mathrm{Ca} 2 p, \mathrm{Sr} 3 p, \mathrm{Na} 1 s, \mathrm{~N}$ $1 s$ core level signals were studied.

Considering C $1 s$ spectra (Fig. 5), in all cases three main signals are evidenced at 284.8, 286.4, and $288.1 \mathrm{eV}$. The first one is assigned to adventitious carbon from surface contamination. The second one at $286.6 \mathrm{eV}$ is the main peak of cellulose, and assigned to $\mathrm{C}-\mathrm{O}$ in alcohol and ether groups; the third one (blue contribution) is attributed to acetal moieties (O-C-O and/or C = O) (Khiari et al. 2017). The chemical shifts relative to $\mathrm{C}$ signal of adventitious carbon were $1.7 \pm 0.1$ and $3.1 \pm 0.1 \mathrm{eV}$, as reported in literature (Dolinina et al. 2017). If the spectra are compared, BC contributions are less evident in the case of $\mathrm{BC} / \mathrm{CaHA}$ indicating that the incorporation of CaHA takes place

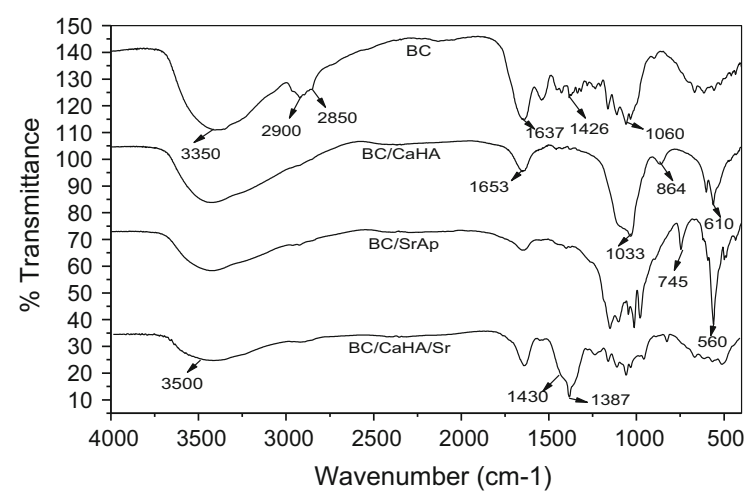

Fig. 3 Vibrational spectra in the infrared region of the hybrid materials BC, BC/CaHA, BC/CaHA/Sr, and BC/SrAp homogenously on the BC surface. Instead, when BC/ CaHA is immersed in a strontium nitrate solution to form $\mathrm{BC} / \mathrm{CaHA}$, some hydroxyapatite is dissolved and the two $\mathrm{C} 1 s$ peaks arising from $\mathrm{BC}$ are much more pronounced confirming what was observed before with other techniques, i.e., some network of cellulose fibres are exposed on the surface.

Considering the $\mathrm{O} 1 s$ signals, in the case of $\mathrm{BC}$ sample only one peak is noticeable at $532.8 \mathrm{eV}$. This binding energy value is similar to that found in literature for cellulose (Dolinina et al. 2017). The signal is broad and should include $\mathrm{O}-\mathrm{C}-\mathrm{O}$ and/or $\mathrm{C}=\mathrm{O}$ and $\mathrm{OH}$ groups. The incorporation of apatites generates a new $\mathrm{O} 1 s$ contribution at ca. $531.1 \mathrm{eV}$ (green contribution) attributed to the corresponding phosphate groups (Hidalgo-Carrillo et al. 2012). As observed in the case of $\mathrm{C} 1 s$ signal, O contribution due to cellulose is less important than that of phosphate in the case of BC/CaHA (See Table 3), but become more important after $\mathrm{Sr}$ incorporation. Moreover, in accordance to $\mathrm{C} 1 s$ signal, in $\mathrm{BC} / \mathrm{SrAp}$ the contributions of $\mathrm{BC}$ are more important indicating that it has not been achieved a homogeneous distribution of SrAp on the $\mathrm{BC}$ surface and some parts of cellulose are exposed on the surface.

Considering the phosphorous signal (Fig. 6), P $2 p$ signal is that much more sensitive to oxidation states; however, $\mathrm{P} 2 p$ signal for $\mathrm{Sr}$ containing samples overlaps with $\mathrm{Sr} 3 d$ core level signal, therefore P $2 s$ spectra have been considered in these two cases, although it is less sensitive to distinguish different oxidation states. BC/CaHA sample exhibits a main $\mathrm{P} 2 p_{3 / 2}$ peak (solid line) at $132.7 \mathrm{eV}$, which is ascribed to phosphate groups in apatites (Hidalgo-Carrillo et al. 2010; Ohtsu et al. 2012). In the case of samples containing $\mathrm{Sr}, \mathrm{P} 2 s$ spectra showed in both cases a main signal centered at ca. $190.5 \mathrm{eV}$, the values reported for HA samples (Shpak et al. 2004). No major 
Table 2 Assignments of FTIR spectra of hybrid materials

a Bhatnagar (1967), Cacicedo et al. (2016), Rehman and Bonfield (1997), Yukhnevich (1973)

\begin{tabular}{ll}
\hline Wavenumber $\left(\mathrm{cm}^{-1}\right)$ & Band assignments $^{\mathrm{a}}$ \\
\hline $3500(\mathrm{BC} / \mathrm{CaHA}, \mathrm{BC} / \mathrm{SrAp}, \mathrm{BC} / \mathrm{CaHA} / \mathrm{Sr})$ & Stretching of $\mathrm{OH}$ groups \\
$1653(\mathrm{BC} / \mathrm{CaHA}, \mathrm{BC} / \mathrm{SrAp}, \mathrm{BC} / \mathrm{CaHA} / \mathrm{Sr})$ & $\mathrm{OH}$ angular deformation of adsorbed water \\
$1430(\mathrm{BC} / \mathrm{CaHA} / \mathrm{Sr})$ & Angular deformation of $\mathrm{CH}_{2}$ \\
$1387(\mathrm{BC} / \mathrm{CaHA} / \mathrm{Sr})$ & Angular deformation of $\mathrm{CH}_{3}$ \\
$1100,1033,950(\mathrm{BC} / \mathrm{CaHA}, \mathrm{BC} / \mathrm{SrAp})$ & Asymmetric deformation of the $\mathrm{PO}_{4}{ }^{3-}$ group \\
$864(\mathrm{BC} / \mathrm{CaHA}) ; 745(\mathrm{BC} / \mathrm{SrAp})$ & $\mathrm{P}-\mathrm{O}(\mathrm{H})$ stretching \\
$610(\mathrm{BC} / \mathrm{CaHA}, \mathrm{BC} / \mathrm{SrAp})$ & Angular deformation of phosphate groups \\
$560(\mathrm{BC} / \mathrm{CaHA}, \mathrm{BC} / \mathrm{SrAp}, \mathrm{BC} / \mathrm{CaHA} / \mathrm{Sr})$ & Asymmetric deformation of $\mathrm{P}-\mathrm{O}(\mathrm{H})$ \\
\hline
\end{tabular}

changes were observed in the position of this band, although was less intense in the case BC/SrAp sample.

Considering Ca $2 p$ spectra (Fig. 7), it is shown two peaks ascribed to the $\mathrm{Ca} 2 p_{3 / 2}-\mathrm{Ca} 2 p_{1 / 2}$ spin orbit doublet, and the binding energy of $\mathrm{Ca} 2 p_{3 / 2}$ component centered in both cases to ca. $347.3 \mathrm{eV}$, also consistent with that reported in the literature for apatites (IdeEktessabi et al. 2005; Hidalgo-Carrillo et al. 2012). The contribution of this signal is much lower in the case of $\mathrm{BC} / \mathrm{CaHA} / \mathrm{Sr}$ compound, as expected due to the incorporation of $\mathrm{Sr}$ and the loss of some calcium apatite during synthesis as exposed above. The $\mathrm{N}$ $1 s$ signal is centered at $399.6 \mathrm{eV}$, which could be due to some remaining amides on the surface. No major changes were observed among the samples. $\mathrm{Na}$ $1 s$ signal is located at $1071.3 \mathrm{eV}$, typical of sodium phosphates such as $\mathrm{Na}_{2} \mathrm{HPO}_{4}$ and $\mathrm{Na}_{3} \mathrm{PO}_{4}$ species (Swift 1982).
The corresponding surface atomic composition is included in Table 3.

As observed from this Table 3, the amount of $\mathrm{P}$ and $\mathrm{Ca}$ present on the surface decreases after $\mathrm{Sr}$ insertion. In the case of $\mathrm{BC} / \mathrm{SrAp}$ sample, a greater surface $\mathrm{Sr}$ exposure is present and explains the lower amount of $\mathrm{P}$ detected on the surface.

From these results it is observed a different surface distribution depending on the sample composition. Thus the sample without $\mathrm{Sr}$ shows an homogeneous distribution of CaHA on the surface, although after $\mathrm{Sr}$ incorporation part of it is dissolved and $\mathrm{BC}$ is exposed on the surface. The sample without $\mathrm{Ca}, \mathrm{BC} / \mathrm{SrAp}$, shows a surface enrichment of $\mathrm{Sr}$ and according to NMR results part of $\mathrm{Sr}$ is forming Sr-phosphate without HA structure.
Fig. $4{ }^{13} \mathrm{C}$ and ${ }^{31} \mathrm{P} \mathrm{CP}-$ MAS spectra of the bacterial cellulose and the hybrid materials produced $(\mathrm{BC} /$ $\mathrm{CaHA}, \mathrm{BC} / \mathrm{CaHA} / \mathrm{Sr}$ and $\mathrm{BC} / \mathrm{SrAp}$ )
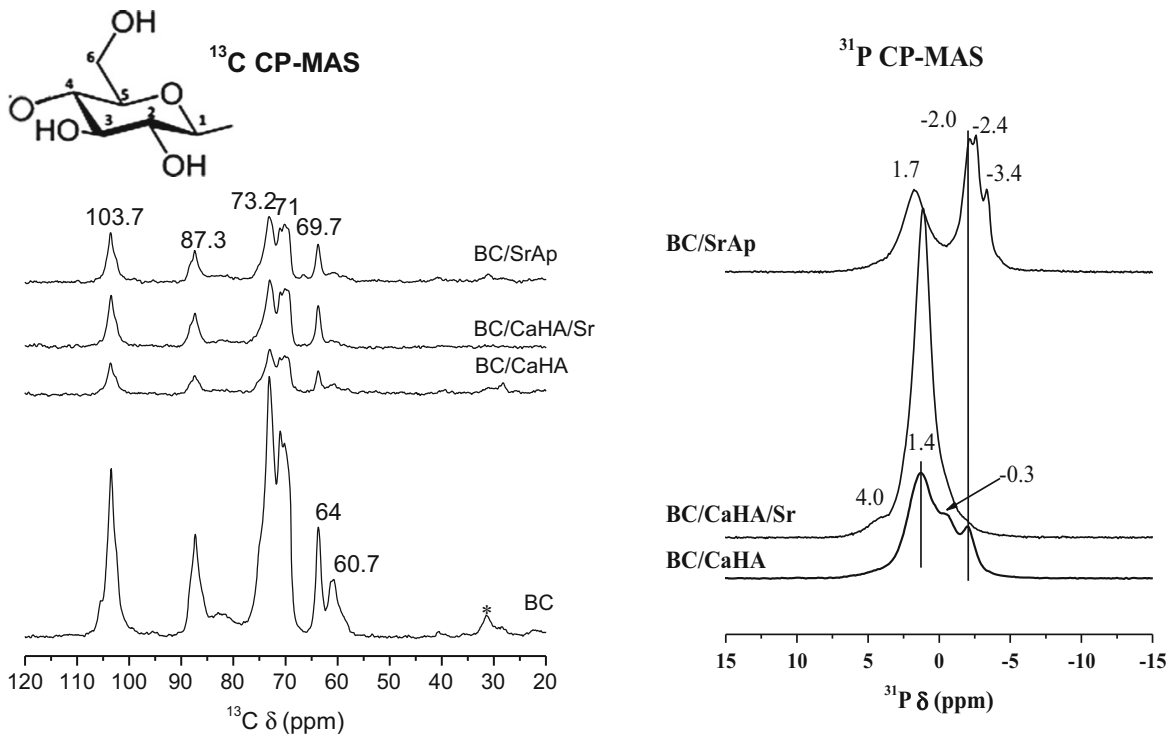
Adsorption studies with the hybrid $\mathrm{BC} / \mathrm{CaHA} / \mathrm{Sr}$

\section{Kinetics of adsorption of Sr ions}

The adsorption kinetics were assessed in order to determine the optimum adsorption time of $\mathrm{Sr}$ ions by the hybrid BC/CaHA. $\mathrm{Sr}^{2+}$ adsorption occurred mainly on the material surface and the adsorbed amount was $17.22 \mathrm{mg}$ of $\mathrm{Sr}$ per gram of adsorbent. The amount of $\mathrm{Sr}^{2+}$ increased rapidly in the first hour and thereafter increased slowly. The equilibrium time, at which adsorption of Srions by the hybrid BC/CaHA became constant, was reached after $2 \mathrm{~h}$ (Fig. 8), indicating that the active sites were completely occupied and showed favorable adsorption kinetics.

Wang et al. (2009) studied the adsorption behavior of $\mathrm{Sr}^{2+}$ on gels from several polysaccharide derivatives, including carboxymethylcellulose (CMC). The authors found that the equilibrium time for $\mathrm{Sr}$ adsorption on CMC was reached at $1 \mathrm{~h}$. In this case, the material showed an adsorption of $99 \mathrm{mg}$ per $\mathrm{g}$ of gel with Lagmuir adjustment, which can be explained by ion exchange mechanisms.

Chen et al. (2009) compared the adsorption of copper and lead ions by pure $\mathrm{BC}$ membranes and $\mathrm{BC}$ membranes containing carboxymethylcellulose (CMC). The adsorption capacity of metal ions by $\mathrm{BC}$ membranes containing CMC (12.63 mg Cu/g and $60.42 \mathrm{mg} \mathrm{Pb} / \mathrm{g}$ ) was higher than that of pure $\mathrm{BC}$ membranes $(9.67 \mathrm{mg} \mathrm{Cu} / \mathrm{g}$ and $22.56 \mathrm{mg} \mathrm{Pb} / \mathrm{g}$ ).
Correlating our results with the results obtained by Chen et al. (2009) it was suggested that the adsorption of strontium increased due to the interaction with calcium hydroxyapatite and this facilitated the ion exchange. Moreover, it is worth noting that the specific surface area and the specific volume of the pores of the $\mathrm{BC} / \mathrm{CaHA} / \mathrm{Sr}$ (Table 1) are higher than that of the pure $\mathrm{BC}$, which can probably improve the accessibility of $\mathrm{Sr}$ ions for the material.

\section{Effect of $p H$}

The $\mathrm{pH}$ of the solution is a key parameter in evaluating the interactions between adsorbate/adsorbent, as it provides information that allows optimization of the conditions for the adsorption system. The adsorbent and adsorbate must be oppositely charged to provide a larger electrostatic interaction between them.

The results in Fig. 9 show that the adsorption capacity was $\mathrm{pH}$-dependent, as there was a reduction in the $\mathrm{Sr}^{2+}$ adsorption when the $\mathrm{pH}$ decreased. The lower adsorption in the acidic solutions is attributed to the $\mathrm{H}^{+}$ions competing with the metal ions for exchange sites. The higher adsorption for the $\mathrm{BC} /$ CaHA hybrid occurred at $\mathrm{pH}$ 6.0. Similar to our result, Nishiyama et al. (2015) also observed the effect of $\mathrm{pH}$ on the $\mathrm{Sr}^{2+}$ adsorption in five types of hydroxyapatite materials and found that with increasing $\mathrm{pH}$ the absorption also increased, and the highest amount of adsorption was reached at $\mathrm{pH} 6.0$.
Fig. $5 \mathrm{C} 1 s$ and $\mathrm{O}$ $1 s$ signals corresponding to a $\mathrm{BC}, \mathbf{b} \mathrm{BC} / \mathrm{CaHA}, \mathbf{c} \mathrm{BC} /$ $\mathrm{CaHA} / \mathrm{Sr}$ and $\mathbf{d} \mathrm{BC} / \mathrm{SrAp}$
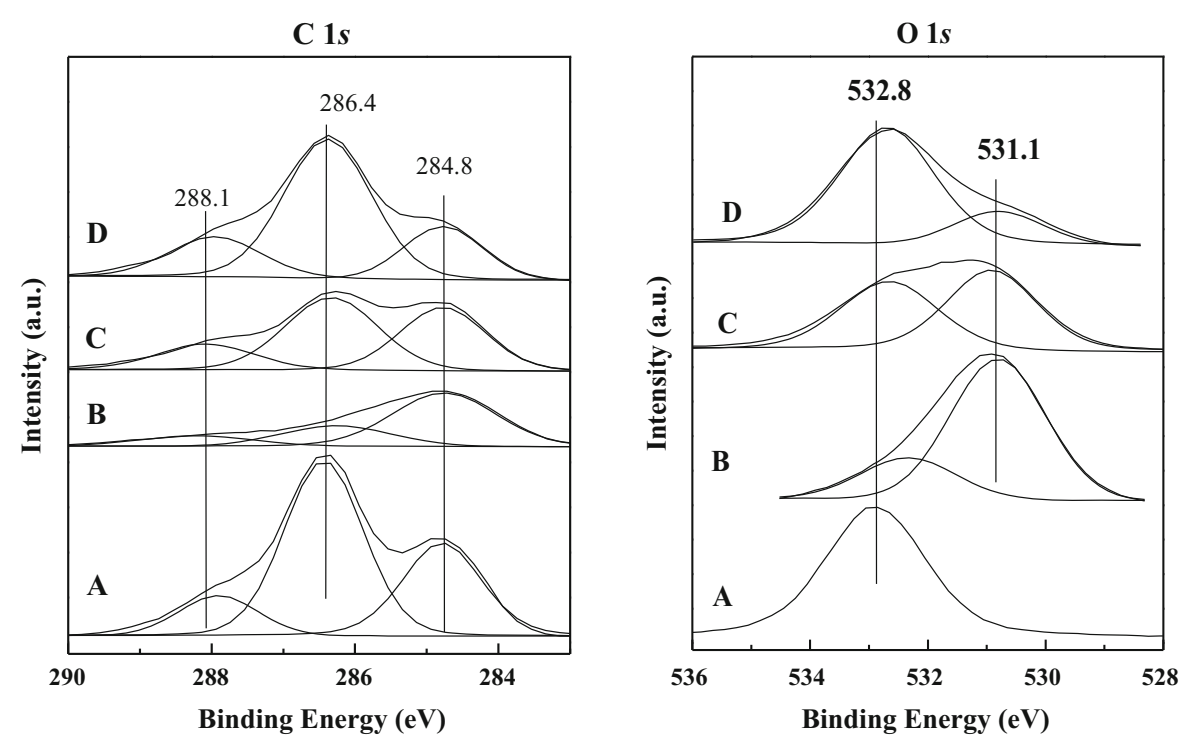
Table 3 Surface composition of the studied materials in atomic concentration $\%$

\begin{tabular}{lllllllllll}
\hline Samples & $\mathrm{C}$ & $\mathrm{O}$ & $\mathrm{Ca}$ & $\mathrm{P}$ & $\mathrm{Sr}$ & $\mathrm{Na}$ & $\mathrm{N}$ & $\mathrm{Ca} / \mathrm{C}$ & $\mathrm{P} / \mathrm{C}$ & $\mathrm{Sr} / \mathrm{C}$ \\
\hline BC & 65.6 & 33.7 & - & - & - & - & - & - & - & - \\
BC/CaHA & 22.5 & 48.9 & 11.6 & 14.2 & - & 0.4 & 2.4 & 0.52 & 0.63 & - \\
BC/CaHA/Sr & 41.0 & 41.6 & 6.4 & 5 & 0.9 & 2.5 & 2.6 & 0.16 & 0.12 & 0.02 \\
BC/SrAp & 52.8 & 34.9 & - & 2.1 & 2.3 & 1.9 & 2.1 & - & 0.04 & 0.04 \\
\hline
\end{tabular}

Fig. $6 \mathrm{P} 2 p$ and $\mathrm{P} 2 s$ core level signals of the hybrid materials produced $(\mathrm{BC} /$ $\mathrm{CaHA}, \mathrm{BC} / \mathrm{CaHA} / \mathrm{Sr}$ and $\mathrm{BC} / \mathrm{SrAp})$

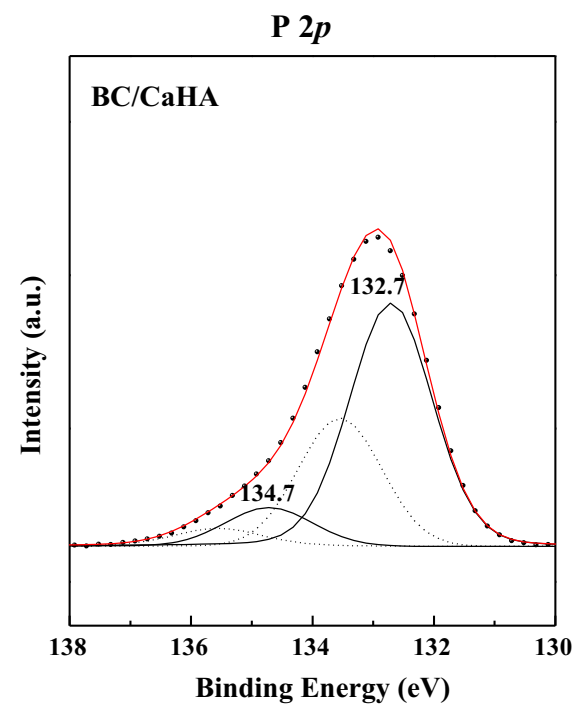

\section{Effect of temperature}

The temperature is considered to be a limiting factor in an adsorption system. The effect of temperature on the adsorption of $\mathrm{Sr}$ ions on the $\mathrm{BC} / \mathrm{CaHA}$ hybrid was evaluated at $20,25,30$, and $40^{\circ} \mathrm{C}$.

The adsorption values obtained at the temperatures 20, 25, 30, and $40{ }^{\circ} \mathrm{C}$ were 9.59, 17.32, 27.93, and $29.36 \mathrm{mg}$ of $\mathrm{Sr}$ per gram of adsorbent, respectively (Fig. 10). Increasing the temperature from 20 to $25^{\circ} \mathrm{C}$ lead to an increase of almost $45 \%$ of the $\mathrm{Sr}^{2+}$ adsorbed amount, and from 25 to $30^{\circ} \mathrm{C}$, an increase in adsorption of around $66 \%$ was observed. However, when the temperature was increased to $40{ }^{\circ} \mathrm{C}$, only a small additional amount of $\mathrm{Sr}$ was adsorbed on the material. This result indicated that $30-40{ }^{\circ} \mathrm{C}$ is the optimum temperature range for $\mathrm{Sr}$ adsorption on the BC/CaHA hybrid.

Theoretically, the adsorbed amount tends to decrease with increasing temperature, because the adsorption processes are generally exothermic (Doğan et al. 2006) stated that the increase in temperature could trigger a change in pore size, facilitating the entry of larger adsorbate particles. The results of this study suggest that another phenomenon would likely be occurring along, such as the exchange of cations, which involves ion exchange of calcium from the hydroxyapatite by the strontium present in the solution.

Similar results were found by Saber-Samandari et al. (2013) who studied the potential of cellulosepolyacrylamide hydroxyapatite composites to eliminate copper ions in water treatment. It was found that by increasing the temperature from 20 to $45^{\circ} \mathrm{C}$, the adsorption capacity increased, with the maximum copper uptake achieved at $45{ }^{\circ} \mathrm{C}$, which indicates that the adsorption of $\mathrm{Cu}^{2+}$ by the composite was an endothermic process, favoring a greater movement of the adsorbate to the adsorbent, contributing to ion exchange phenomena.

\section{Adsorption isotherm}

Adsorption isotherm studies are important to determine the efficacy of adsorption. The equilibrium adsorption isotherm is fundamental to describe the 

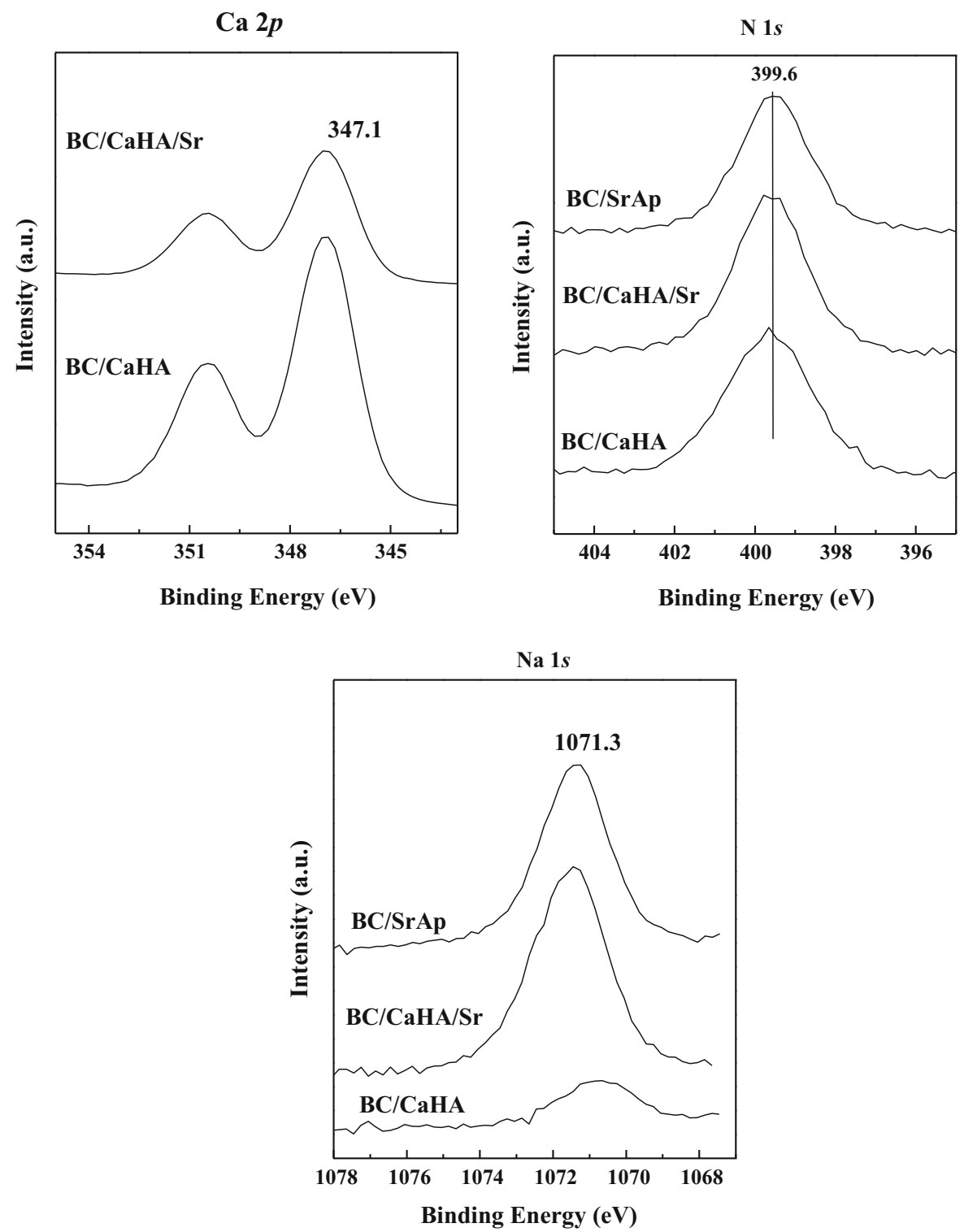

Fig. $7 \mathrm{Ca} 2 \mathrm{p}, \mathrm{N}$ 1s, Na 1s core level signals of the hybrid materials produced (BC/CaHA, BC/CaHA/Sr and BC/SrAp)

interactive behavior between the adsorbate and adsorbent, and the concentration of adsorbed and dissolved adsorbate at equilibrium. Adsorption equilibrium data have been fitted to the Langmuir model, which is commonly used to describe experimental results in a wide range of concentrations. From the isotherms (Fig. 11), it was noted that the maximum adsorption capacity is directly proportional to the temperature increase.

This isotherm profile is considered favorable to adsorption. The increase in adsorption with increasing temperature suggests that there is a transition from physical adsorption to chemical adsorption most likely caused by the entropy variations (Sousa et al. 2014).

Incorporation of SrAp in BC matrix (production of the hybrid $B C / S r A p$ )

As exhibiting in Fig. 12, the total amount of strontium that was incorporated increased after each cycle, although after the third cycle only minor amounts were additionally incorporated as the active sites in the 


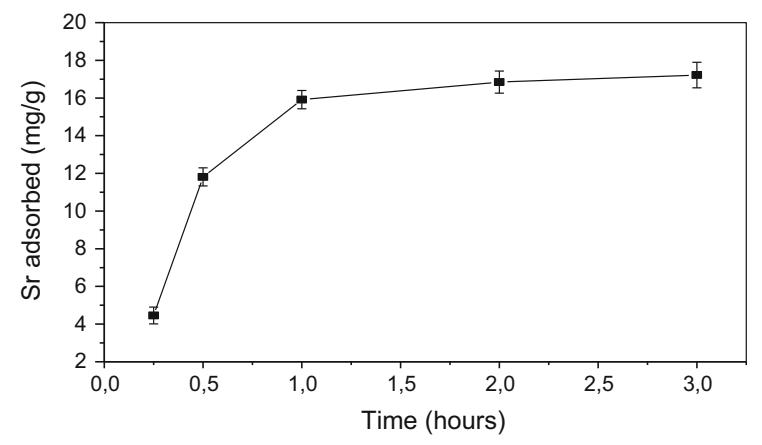

Fig. 8 Adsorption kinetics of $\mathrm{Sr}^{2+}$ by $\mathrm{BC} / \mathrm{CaHA}$ as a function of time

matrix were being occupied. The formation of strontium apatite was confirmed due to the reduction in the residual concentration of strontium in the solution. During the alternate soaking of BC in strontium nitrate solution and dibasic sodium phosphate solution, the apatite was formed by chemical precipitation and synthesis of strontium phosphates. When the BC membranes were immersed in $\mathrm{SrCl}_{2}$ solution at $1000 \mathrm{mg} / \mathrm{L}$, a greater incorporation of $\mathrm{Sr}$ was observed, reaching $237.32 \mathrm{mg}$ of $\mathrm{Sr}$ per gram of BC after the five cycles, while after five cycles of immersion in $\mathrm{SrCl}_{2}$ solution at $100 \mathrm{mg} / \mathrm{L}$, an incorporation of $109.54 \mathrm{mg} / \mathrm{g}$ of adsorbent was achieved.

The BC/SrAp hybrid material was obtained by chemical precipitation of $\mathrm{P}$ and $\mathrm{Sr}$ ions with the formation of strontium phosphate on the surface of BC. Therefore, Sr was tightly bound to the material surface, since an ionic bond occurred between the metal and the non-metal surface. Thus, the cellulose matrix containing free hydroxyl $\left(\mathrm{OH}^{-}\right)$groups

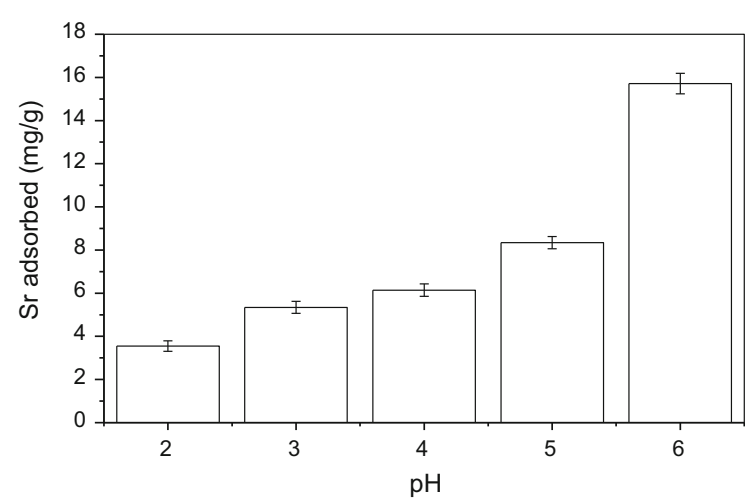

Fig. 9 Effect of $\mathrm{pH}$ variation on the adsorption of $\mathrm{Sr}^{2+}$ on the hybrid $\mathrm{BC} / \mathrm{CaHA}$ interacted with $\mathrm{Sr}^{2+}$ (positively charged), forming an ionic bond. At the same time, the phosphate ions $\left(\mathrm{PO}_{4}{ }^{3-}\right)$ could bind to the $\mathrm{Sr}^{2+}$. It has been suggested that during the formation of the $\mathrm{BC} / \mathrm{SrAp}$ composite, several interactions and intermolecular forces are at play.

NMR analysis confirmed that the BC/SrAp hybrid formed had strontium phosphates chemically bound to bacterial cellulose, indicating chemical adsorption on the material. XPS analysis showed that the formation of strontium phosphates is not similar to that of calcium hydroxyapatite, indicating that strontium delays the formation of the hydroxyapatite phase.

\section{Desorption study}

From the results presented, it can be observed that for hybrid $\mathrm{BC} / \mathrm{CaHA} / \mathrm{Sr}$, the condition which lead to higher $\mathrm{Sr}^{2+}$ adsorption $(23.02 \pm 1.14 \mathrm{mg} / \mathrm{g})$ occurred when the $\mathrm{BC}$ membrane was immersed in strontium nitrate solution for $2 \mathrm{~h}$ at $40{ }^{\circ} \mathrm{C}$ and $\mathrm{pH}$ 6. While for the hybrid BC/SrAp, the highest amount of incorporated $\mathrm{Sr}(237.31 \pm 0.42 \mathrm{mg} / \mathrm{g})$ occurred after five immersion cycles in strontium chloride solution at a concentration of $1000 \mathrm{mg} / \mathrm{L}$.

The desorption studies were performed in order to obtain the $\mathrm{Sr}$ release profile by the hybrid materials produced at these optimized conditions. The hybrid $\mathrm{BC} / \mathrm{CaHA} / \mathrm{Sr}$ released $6.77 \mathrm{mg} / \mathrm{g}$ of $\mathrm{Sr}$ after 7 days and $21 \mathrm{mg} / \mathrm{g}$ after 120 days (Fig. 13). This faster elution probably indicates that the $\mathrm{Sr}$ ions were adsorbed on the BC/CaHA/Sr by physisorption mechanisms. The hybrid BC/SrAp showed a slower release profile than the $\mathrm{BC} / \mathrm{CaHA} / \mathrm{Sr}$. After 7 days, the

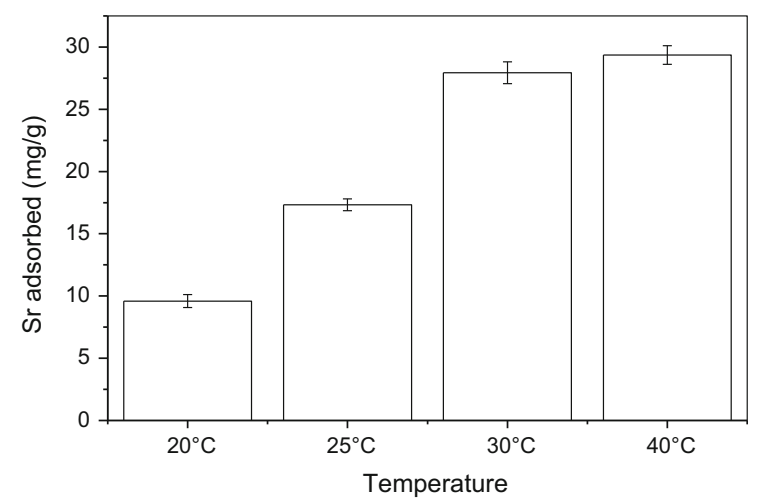

Fig. 10 Effect of temperature on the adsorption of $\mathrm{Sr}^{2+}$ by BC/ CaHA hybrid 
material eluted $6 \mathrm{mg} / \mathrm{g}$ of the adsorbed $\mathrm{Sr}$, and after 120 days, only $44 \mathrm{mg} / \mathrm{g}$ of $\mathrm{Sr}$ was released.

Table 4 shows the $\mathrm{Sr}$ release rate per day at different periods during the experiment. On the first day, the release rate was 12.7 and $9.2 \mathrm{mg} / \mathrm{g}$ for $\mathrm{BC} /$ $\mathrm{CaHA} / \mathrm{Sr}$ and $\mathrm{BC} / \mathrm{SrAp}$, respectively. During the following weeks, the daily release rate decreased for both materials and after 16 weeks (120 days), reached values of 0.004 and $0.06 \mathrm{mg} / \mathrm{g}$ per day for $\mathrm{BC} / \mathrm{CaHA} /$ $\mathrm{Sr}$ and $\mathrm{BC} / \mathrm{SrAp}$, respectively.

The results indicated that the synthesis route for the production of the $\mathrm{BC} / \mathrm{SrAp}$ hybrid promoted not only a greater incorporation of $\mathrm{Sr}$ into the $\mathrm{BC}$ structure, but also produced a material with a slower $\mathrm{Sr}$ release profile (retaining about $94 \%$ of $\mathrm{Sr}$ after 120 days). This slower elution probably indicates that the Srions were adsorbed on the BC/SrAp by chemisorption mechanisms. These features make the BC/SrAp a potential material for use in applications where the release of $\mathrm{Sr}$ at the implant site should be controlled.

Tiwari et al. (2012) studied drug release mechanisms and found that in order to reach the best therapeutic efficacy, decreased toxicity, and increased time of action, it is important to create systems with a slow release profile (controlled delivery) of active compounds, which ensures a safer administration and lower dosage of the drug. However, in order to combat infections or inflammation, sometimes an initial high dosage is essential, and a large amount of drug must be released quickly at the beginning of the treatment (Vallet-Regí et al. 2007).

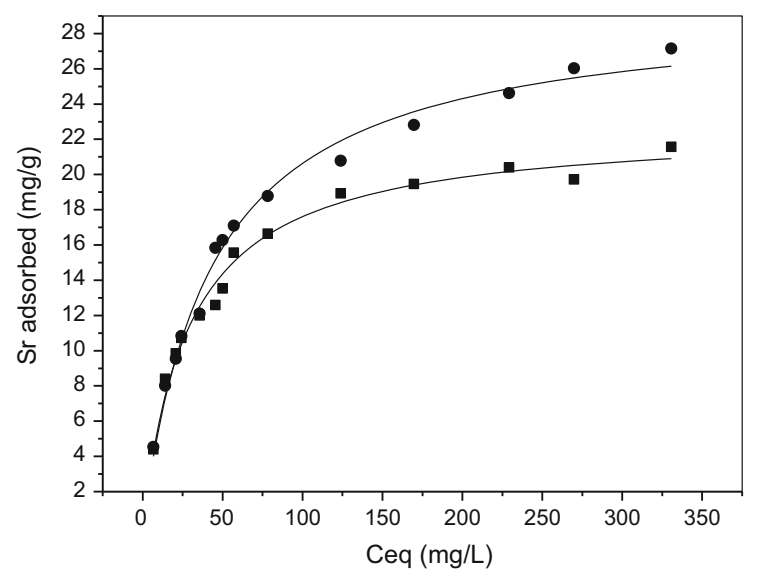

Fig. 11 Adsorption isotherms of $\mathrm{Sr}^{2+}$ (concentration of $10-350 \mathrm{mg} / \mathrm{L})$ on BC/CaHA at $\mathrm{pH} 6.0$ and temperatures of $25^{\circ} \mathrm{C}(\boldsymbol{\square})$ and $40{ }^{\circ} \mathrm{C}(\boldsymbol{\bullet})$
Energy-dispersive X-ray spectroscopy (EDX)

The MEV/EDX technique was used to verify the surface composition of the samples before and after strontium desorption, in addition to identifying the type of calcium phosphates produced on the surface through the $\mathrm{Ca} / \mathrm{P}$ ratio.

In the $\mathrm{BC} / \mathrm{SrAp}$ and $\mathrm{BC} / \mathrm{CaHA} / \mathrm{Sr}$ samples the deposition of the strontium phosphates and calcium phosphates on the surfaces is confirmed (Fig. 14a, c), showing that the immersion cycles method favors the chemical precipitation of hydroxyapatite. After the strontium desorption assay, the percentage of each component present on the surface of these samples was quantified.

Through the micrographs (Fig. 14b, d), it can be seen that after the desorption assay the samples immersed in PBS buffer showed agglomerations on their surface, possibly referring to the salt crystals
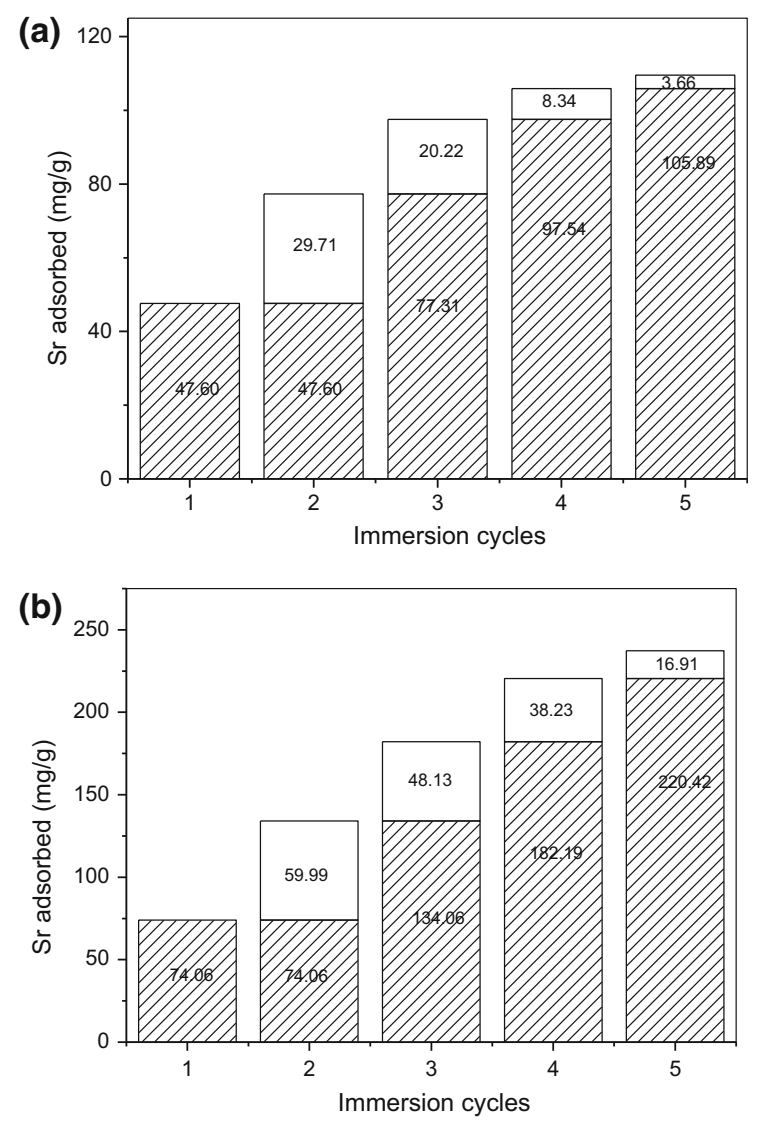

Fig. 12 Determination of SrAp incorporation in the BC matrix after each immersion cycle in strontium nitrate solution at concentrations of $100 \mathrm{mg} / \mathrm{L} \mathrm{(a)} \mathrm{and} 1000 \mathrm{mg} / \mathrm{L} \mathrm{(b)}$ 
from the buffer itself. In fact, as confirmed by the EDS analysis (Fig. 14b, d), there was a significant increase in the amount of elements such as $\mathrm{Na}$ and $\mathrm{Cl}$ in the samples after the desorption assay.

In the sample BC/SrAp (Fig. 14a), elements such as oxygen and carbon were detected by EDS, which are typical of the cellulose structure. On the other hand, the phosphorus and strontium detected came from the chemical precipitation step during the deposition of strontium apatite on BC fibres. The major component (41.7\%) found in BC/SrAp sample before the desorption study was Sr. Meanwhile, after the desorption assay, only $13.2 \%$ of $\mathrm{Sr}$ was found on the sample surface (Fig. 14b), confirming the release of strontium.

In $\mathrm{BC} / \mathrm{CaHA} / \mathrm{Sr}$ samples (Fig. 14c) the followings elements were detected: oxygen, carbon, phosphorus and strontium, a high amount (38\%) of calcium and traces of sodium and chlorine. The stoichiometric ratio of $2.27 \mathrm{Ca} / \mathrm{P}$, which suggests that the hydroxyapatite deposited on the material are tetracalcium phosphates. The strontium content (4\%) was well below that of calcium, probably because $\mathrm{Sr}$ was incorporated by physical adsorption, where it had to compete by the active sites with the calcium already present on the surface.

When the BC/CaHA/Sr sample was submitted to the desorption assay, the calcium contents decreased and the sodium and chlorine contents increased. Only traces of strontium were found, confirming that this element was desorbed throughout the days (Fig. 14d). The traces of aluminium detected are likely to come from contamination during preparation of the samples for analysis.

\section{Conclusions}

This work describes for the first time the production of hybrids based on bacterial cellulose and hydroxyapatite as a controlled strontium delivery systems, favoring biomaterial research aimed at future applications in guided bone regeneration.

Bacterial cellulose/hydroxyapatite hybrid materials were produced via two routes of synthesis. These materials are able to incorporate strontium through distinct adsorption/desorption profiles for each material that involved physisorption and chemisorption mechanisms.

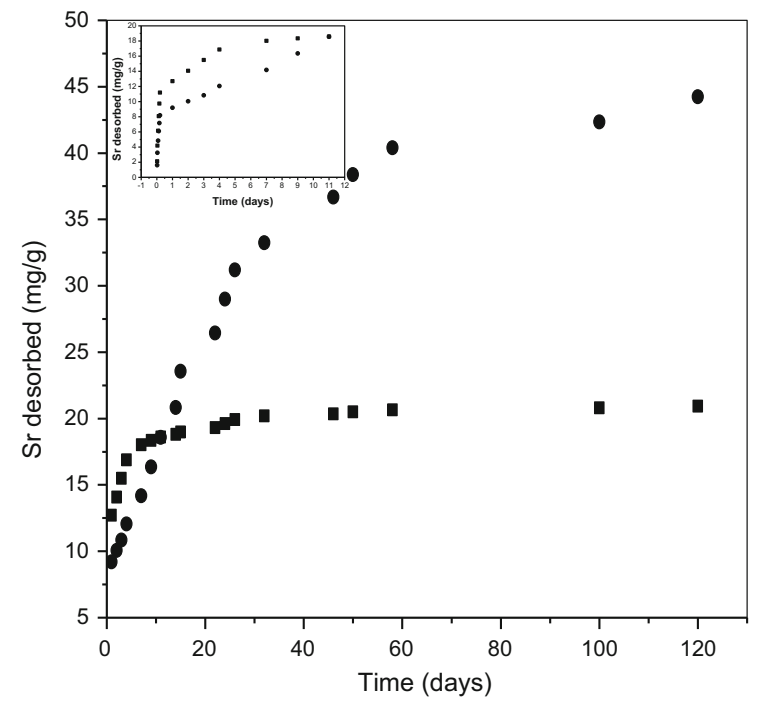

Fig. 13 Strontium desorption from the hybrid materials at optimized conditions observed for a duration of 120 days. Circle markers (BC/SrAp O) and Square markers (BC/CaHA/Sr $\mathbf{\square})$. The small graphic reports the $\mathrm{Sr}^{2+}$ desorption during the first $5 \mathrm{~h}$ of the experiment. The arrows indicate that after 120 days, the percentages of $\mathrm{Sr}$ desorbed were 6 and $91 \%$ for BC/SrAp and $\mathrm{BC} / \mathrm{CaHA} / \mathrm{Sr}$, respectively

The BC/SrAp material exhibited increases strontium adsorption capacity and its release was slow and controlled because of the strong chemical bond formed between the metal and the cellulose matrix/ hydroxyapatite, ensuring controlled doses for a period of over 4 months. Hence, this material is a promising strontium delivery system to assist bone-remodeling mechanism during GBR therapeutic protocol. Subsequently, in vivo studies are required to evaluate the

Table 4 Strontium release rate/day from hybrid materials studied for a duration of 16 weeks (120 days)

\begin{tabular}{lll}
\hline Period & \multicolumn{2}{l}{ Release rate/day $(\mathrm{mg} / \mathrm{g})^{\mathrm{a}}$} \\
\cline { 2 - 3 } & BC/CaHA/Sr & BC/SrAp \\
\hline 1st day & 12.7 & 9.2 \\
1st week & 1.13 & 0.99 \\
2nd week & 0.14 & 0.95 \\
3rd week & 0.07 & 0.7 \\
4-6th week & 0.03 & 0.4 \\
7-16th week & 0.004 & 0.06 \\
\hline
\end{tabular}

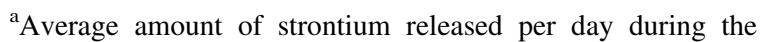
indicated period 

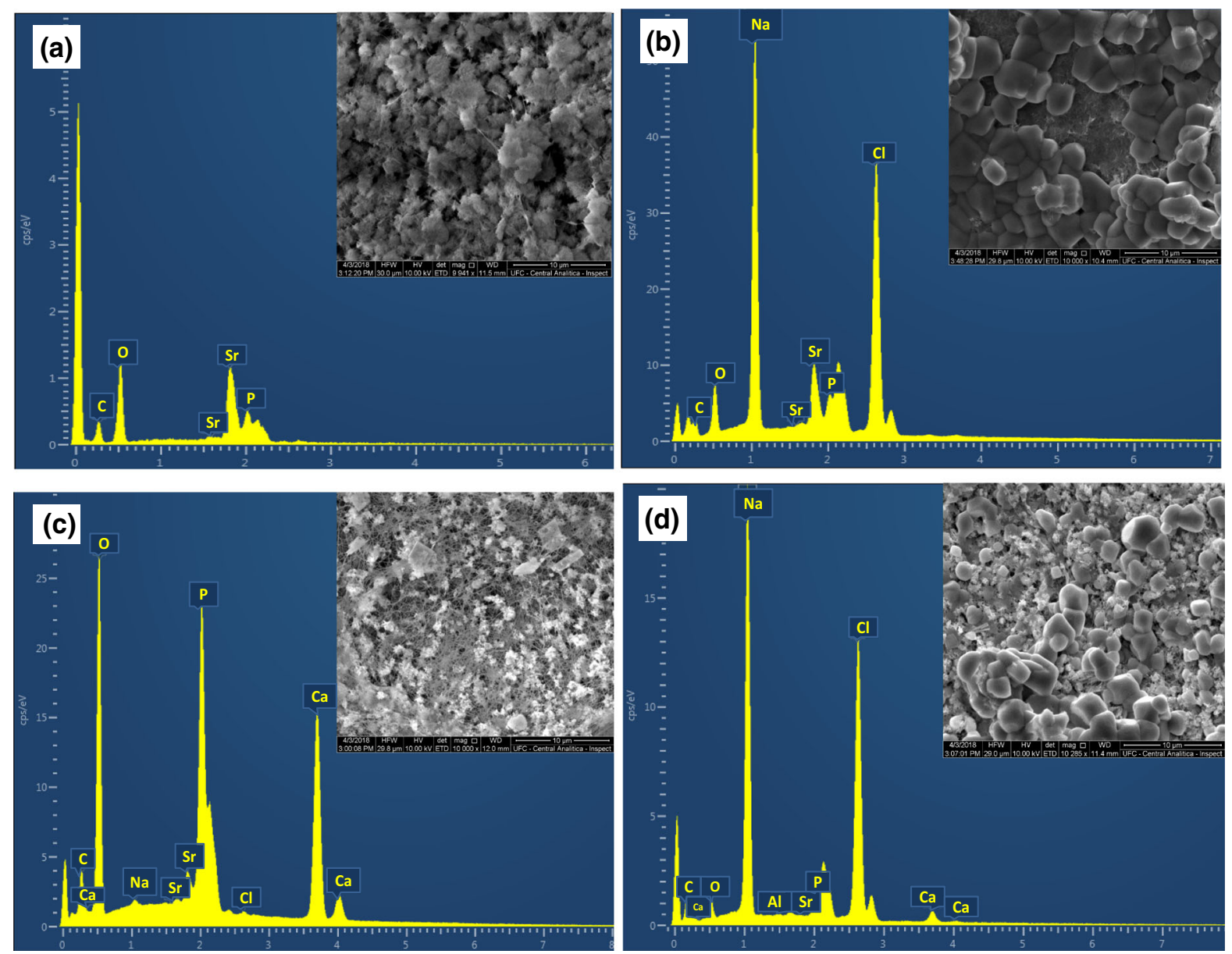

Fig. 14 Electron micrographs and energy-dispersive X-ray spectroscopy of the surfaces of $\mathbf{a}, \mathbf{b} \mathrm{BC} / \mathrm{SrAp}$ and $\mathbf{c}, \mathbf{d ~ B C / C a H A / S r}$, before (a and $\mathbf{c}$ ) and after (b and $\mathbf{d})$ the desorption of $\mathrm{Sr}$

biocompatibility and the therapeutic efficacy of the materials produced.

Acknowledgments The authors would like to thank the Coordination for the Improvement of Higher Education Personnel (CAPES), National Counsel of Technological and Scientific Development (CNPq), Cearense Foundation for the Support of Scientific and Technological Development (FUNCAP), and the Embrapa Agroindústria Tropical for funding this research. This research was also supported by the following projects: FUNCAP/CNPq (PR2-0101-00023.01.00/ 15), CNPq (No. 305504/2016-9), PROCAD/CAPES (88881.068439/2014-01) and CTQ2015-68951-C3-3R (Ministerio de Economía y Competitividad, Spain and FEDER Funds). A.I.M. thanks the Ministry of Economy and Competitiveness for a Ramón y Cajal contract (RyC201517870).

\section{References}

Ahn SJ et al (2015) Characterization of hydroxyapatite-coated bacterial cellulose scaffold for bone tissue engineering. Biotechnol Bioprocess Eng 20:948-955. https://doi.org/10. 1007/s12257-015-0176-z

Bhatnagar VM (1967) Infrared spectrum of strontium hydroxyapatit. Experientia 23:697-699. https://doi.org/10.1007/ bf02154118

Brunauer S, Emmett PH, Teller E (1938) Adsorption of gases in multimolecular layers. J Am Chem Soc 60:309-319. https://doi.org/10.1021/ja01269a023

Cacicedo ML et al (2016) Modified bacterial cellulose scaffolds for localized doxorubicin release in human colorectal HT29 cells. Colloids Surf B 140:421-429. https://doi.org/10. 1016/j.colsurfb.2016.01.007

Capitani D, Crescenzi V, De Angelis AA, Segre AL (2001) Water in hydrogels. an nmr study of water/polymer interactions in weakly cross-linked chitosan networks. Macromolecules 34:4136-4144. https://doi.org/10.1021/ ma002109x 
Ceratti DR et al (2015) Critical effect of pore characteristics on capillary infiltration in mesoporous films. Nanoscale 7:5371-5382. https://doi.org/10.1039/c4nr03021d

Chen S et al (2009) Carboxymethylated-bacterial cellulose for copper and lead ion removal. J Hazard Mater 161:1355-1359. https://doi.org/10.1016/j.jhazmat.2008. 04.098

Chen Y et al (2012) Role of calcium in metalloenzymes: effects of calcium removal on the axial ligation geometry and magnetic properties of the catalytic diheme center in MauG. Biochemistry 51:1586-1597. https://doi.org/10. 1021/bi201575f

Doğan M et al (2006) Adsorption kinetics of maxilon blue GRL onto sepiolite from aqueous solutions. Chem Eng. J 124:89-101. https://doi.org/10.1016/j.cej.2006.08.016

Dolinina ES et al (2017) Effect of trehalose on structural state of bovine serum albumin adsorbed onto mesoporous silica and the protein release kinetics in vitro. Colloids Surf A 527:101-108. https://doi.org/10.1016/j.colsurfa.2017.05. 014

Duarte EB et al (2015) Production of hydroxyapatite-bacterial cellulose nanocomposites from agroindustrial wastes. Cellulose 22:3177-3187. https://doi.org/10.1007/s10570015-0734-8

Dufresne A (2012) Nanocellulose: from nature to high performance tailored materials. E-book. Walter de Gruyter, Berlin

Foresti ML, Vázquez A, Boury B (2017) Applications of bacterial cellulose as precursor of carbon and composites with metal oxide, metal sulfide and metal nanoparticles: a review of recent advances. Carbohydr Polym 157:447-467. https://doi.org/10.1016/j.carbpol.2016.09. 008

Gea $S$ et al (2011) Investigation into the structural, morphological, mechanical and thermal behaviour of bacterial cellulose after a two-step purification process. Bioresour Technol 102:9105-9110. https://doi.org/10.1016/j. biortech.2011.04.077

Grande CJ et al (2009) Nanocomposites of bacterial cellulose/ hydroxyapatite for biomedical applications. Acta Biomater 5:1605-1615. https://doi.org/10.1016/j.actbio.2009.01.022

Heinze T, Liebert T, Koschella A (2014) Esterification of polysaccharides. Springer, Berlin

Henderson CMB et al (2016) X-ray absorption study of $3 \mathrm{~d}$ transition-metals and $\mathrm{Mg}$ in glasses and analogue crystalline materials in A Fe $3+\mathrm{Si} 2 \mathrm{O} 6$ and $\mathrm{A} 2 \mathrm{X} 2+\mathrm{Si} 5 \mathrm{O}$ 12 , where $\mathrm{A}=\mathrm{K}, \mathrm{Rb}$, or $\mathrm{Cs}$ and $\mathrm{X}=\mathrm{Mg}, \mathrm{Mn}, \mathrm{Fe} \mathrm{Co}, \mathrm{Ni}$, $\mathrm{Cu}$, or Zn. J Non-Cryst Solids 451:23-48. https://doi.org/ 10.1016/j.jnoncrysol.2016.05.016

Hestrin S, Schramm M (1954) Synthesis of cellulose by Acetobacte rxylinum. Preparation of freeze-dried cells capable of polymerizing glucose to cellulose. Biochem $\mathrm{J}$ 58:345-352

Hidalgo-Carrillo J et al (2010) A study on the potential application of natural phosphate in photocatalytic processes. J Colloid Interface Sci 344:475-481. https://doi.org/10. 1016/j.jcis.2010.01.020

Hidalgo-Carrillo J et al (2012) XPS evidence for structureperformance relationship in selective hydrogenation of crotonaldehyde to crotyl alcohol on platinum systems supported on natural phosphates. J Colloid Interface Sci 382:67-73. https://doi.org/10.1016/j.jcis.2012.05.050

Hing KA (2005) Bioceramic bone graft substitutes: influence of porosity and chemistry. Int $\mathbf{J}$ App Ceram Technol 2:184-199. https://doi.org/10.1111/j.1744-7402.2005. 02020.x

Hutchens S (2007). Characterization of a biomimetic calciumdeficient hydroxyapatite-bacterial cellulose composite. Ph.D. Dissertation, University of Tennessee

Hutchens S et al (2006) Biomimetic synthesis of calcium-deficient hydroxyapatite in a natural hydrogel. Biomaterials 27:4661-4670. https://doi.org/10.1016/j.biomaterials. 2006.04.032

Ide-Ektessabi A, Yamaguchi T, Tanaka Y (2005) RBS and XPS analyses of the composite calcium phosphate coatings for biomedical applications. Nucl Instrum Methods Phys Res B 241:685-688. https://doi.org/10.1016/j.nimb.2005.07. 165

Khiari R et al (2017) Synthesis and characterization of cellulose carbonate using greenchemistry: surface modification of Avicel. Carbohyd Polym 163:254-260. https://doi.org/10. 1016/j.carbpol.2017.01.037

Lin KSK et al (2005) Mechanistic study of apatite formation on bioactive glass surface using31P solid-state NMR spectroscopy. Chem Mater 17:4493-4501. https://doi.org/10. $1021 / \mathrm{cm} 050654 \mathrm{c}$

Liu Y et al (2005) Crosslinked organic-inorganic hybrid chitosan membranes for pervaporation dehydration of isopropanol-water mixtures with a long-term stability. J Membr Sci 251:233-238. https://doi.org/10.1016/j. memsci.2004.12.003

Marie PJ, Felsenberg D, Brandi ML (2010) How strontium ranelate, via opposite effects on bone resorption and formation, prevents osteoporosis. Osteoporos Int 22:1659-1667. https://doi.org/10.1007/s00198-010-13690

Melnikov P, Gonçalves RV (2015) Preparation and characterization of strontium hydroxyapatite $\mathrm{Sr} 10\left(\mathrm{PO}_{4}\right) 6(-$ $\mathrm{OH}) 2 \cdot 10 \mathrm{H} 2 \mathrm{O}$ suitable for orthopedic applications. Mater Lett 150:89-92. https://doi.org/10.1016/j.matlet.2015.02. 110

Nishiyama Y et al (2015) Adsorption and removal of strontium in aqueous solution by synthetic hydroxyapatite. J Radioanal Nucl Chem 307:1279-1285. https://doi.org/10. 1007/s10967-015-4228-9

Ohtsu N, Nakamura Y, Semboshi S (2012) Thin hydroxyapatite coating on titanium fabricated by chemical coating process using calcium phosphate slurry. Surf Coat Technol 206:2616-2621. https://doi.org/10.1016/j.surfcoat.2011. 11.022

Pan HB et al (2009) Solubility of strontium-substituted apatite by solid titration. Acta Biomater 5:1678-1685. https://doi. org/10.1016/j.actbio.2008.11.032

Pértile RAN et al (2012) Bacterial cellulose: long-term biocompatibility studies. J Biomater Sci Polym 23:1-16. https://doi.org/10.1163/092050611x581516

Pigossi SC et al (2015) Bacterial cellulose-hydroxyapatite composites with osteogenic growth peptide (OGP) or pentapeptide OGP on bone regeneration in critical-size calvarial defect model. J Biomed Mater Res 103:3397-3406. https://doi.org/10.1002/jbm.a.35472 
Querido W, Rossi AL, Farina M (2016) The effects of strontium on bone mineral: a review on current knowledge and microanalytical approaches. Micron 80:122-134. https:// doi.org/10.1016/j.micron.2015.10.006

Rad MM et al (2017) Fabrication and characterization of twolayered nanofibrous membrane for guided bone and tissue regeneration application. Mater Sci Eng C 80:75-87. https://doi.org/10.1016/j.msec.2017.05.125

Rajwade JM, Paknikar KM, Kumbhar JV (2015) Applications of bacterial cellulose and its composites in biomedicine. Appl Microbiol Biotechnol 99:2491-2511. https://doi.org/10. 1007/s00253-015-6426-3

Rakhmatia YD et al (2013) Current barrier membranes: titanium mesh and other membranes for guided bone regeneration in dental applications. J Prosthodont Res 57:3-14. https://doi. org/10.1016/j.jpor.2012.12.001

Rehman I, Bonfield W (1997) Characterization of hydroxyapatite and carbonated apatite by photo acoustic FTIR spectroscopy. J Mater Sci Mater Med 8:1-4. https://doi.org/10. 1023/a:1018570213546

Retzepi M, Donos N (2010) Guided bone regeneration: biological principle and therapeutic applications. Clin Oral Implants Res 21:567-576. https://doi.org/10.1111/j.16000501.2010.01922.x

Saber-Samandari S, Saber-Samandari S, Gazi M (2013) Cellulose-graft-polyacrylamide/hydroxyapatite composite hydrogel with possible application in removal of $\mathrm{Cu}$ (II) ions. React Funct Polym 73:1523-1530. https://doi.org/10. 1016/j.reactfunctpolym.2013.07.007

Saska S et al (2011) Bacterial cellulose-hydroxyapatite nanocomposites for bone regeneration. Int $\mathrm{J}$ Biomater 2011:1-8. https://doi.org/10.1155/2011/175362

Schumacher M et al (2016) Strontium substitution in apatitic $\mathrm{CaP}$ cements effectively attenuates osteoclastic resorption but does not inhibit osteoclastogenesis. Acta Biomater 37:184-194. https://doi.org/10.1016/j.actbio.2016.04.016

Shpak AP, Karbovskii VL, Vakhney AG (2004) Electronic structure of isomorphically substituted strontium apatite. J Electron Spectrosc Relat Phenom 137-140:585-589. https://doi.org/10.1016/j.elspec.2004.02.056

Sousa RCS et al (2014) Adsorption of alpha-lactalbumin from milk whey on hydroxyapatite: effect of ph and temperature and thermodynamic analysis. Quím Nova 37:950-955. https://doi.org/10.5935/0100-4042.20140149

Sugiyama S (2003) Enhancement of the catalytic activities in propane oxidation and H-D exchangeability of hydroxyl groups by the incorporation with cobalt into strontium hydroxyapatite. J Catal 214:8-14. https://doi.org/10.1016/ s0021-9517(02)00101-x

Swift P (1982) Adventitious carbon-the panacea for energy referencing? Surf Interface Anal 4:47-51. https://doi.org/ 10.1002/sia.740040204

Tiwari G et al (2012) Drug delivery systems: an updated review. Int J Pharma Investig 2:2-11. https://doi.org/10.4103/ 2230-973x.96920

Ummartyotin S, Thiangtham S, Manuspiya H (2017) Strontiummodified bacterial cellulose and a polyvinylidene fluoride composite as an electroactive material. For Prod J 67:288-296. https://doi.org/10.13073/fpj-d-16-00041

Vallet-Regí M, Ruiz-Hernández E (2011) Bioceramics: from bone regeneration to cancer nanomedicine. Adv Mater 23:5177-5218. https://doi.org/10.1002/adma.201101586

Vallet-Regí M, Balas F, Arcos D (2007) Mesoporous materials for drug delivery. Angew Chem Int Ed 46:7548-7558. https://doi.org/10.1002/anie.200604488

Venugopal A, Scurrell MS (2003) Hydroxyapatite as a novel support for gold and ruthenium catalysts behaviour in the water gas shift reaction. Appl Catal 245:137-147. https:// doi.org/10.1016/s0926-860x(02)00647-6

Wang X et al (2009) Towards predicting Ca2 + -binding sites with different coordination numbers in proteins with atomic resolution. Proteins Struct Funct Bioinform 75:787-798. https://doi.org/10.1002/prot.22285

Yukhnevich GV (1973) Infrared spectroscopy of water. Nauka, Moscow

Zeng X, Ruckenstein E (1996) Control of pore sizes in macroporous chitosan and chitin membranes. Ind Eng Chem Res 35:4169-4175. https://doi.org/10.1021/ie960270j

Zhang W et al (2011) Effects of strontium in modified biomaterials. Acta Biomater 7:800-808. https://doi.org/10.1016/ j.actbio.2010.08.031

Zhang H et al (2014) Universal influenza vaccines, a dream to be realized soon. Viruses 6:1974-1991. https://doi.org/10. $3390 / v 6051974$

Zhong LR et al (2013) Nitric oxide regulates neuronal activity via calcium-activated potassium channels. PLoS ONE 8:1-12. https://doi.org/10.1371/journal.pone.0078727

Zhou Y et al (2012) Probing Ca2 + -binding capability of viral proteins with the EF-hand motif by grafting approach. Methods Mol Biol 963:37-53. https://doi.org/10.1007/ 978-1-62703-230-8_3

Zimmermann KA et al (2011) Biomimetic design of a bacterial cellulose/hydroxyapatite nanocomposite for bone healing applications. Mater Sci Eng C 31:43-49. https://doi.org/10. 1016/j.msec.2009.10.007 